\title{
Exploring New Forms with Parametric Patterns for Responsive Facades
}

\author{
A Case on Kinetic Jali Design
}

\author{
Mahina Reki ${ }^{* *}$, Semra Arslan Selçuk ${ }^{2}$ \\ 1 Department of Architecture, Faculty of Architecture, National College of Arts, 54000 Lahore, 04 Shahrah-E-Quaid-E-Azam, \\ Pakistan \\ 2 Department of Architecture, Faculty of Architecture, Gazi University, 06570 Çankaya, Ankara, 5 Eti Yükseliş Sk., Turkey \\ * Corresponding author, e-mail: mahina.reki@nca.edu.pk
}

Received: 25 December 2020, Accepted: 27 October 2021, Published online: 01 December 2021

\begin{abstract}
Façades or building envelopes have always been the interface between the building and the environment. The effective and smart façades that are designed to adapt the environmental conditions date back to when windows and ventilators were designed carefully in response to the site conditions. Over recent decades, the emphasis on energy consumption and its reduction has increased drastically, as technology has evolved and increasingly new materials are used in buildings than ever. Due to the numerous significant roles that a facade plays, thermal comfort, aesthetics, acoustics and lighting, high-performance building facades have become one of the main focal points for researchers and designers. This study is based on the intersection of two main subjects of interest, the significance of jali/screens, as ornate architectural elements along with their functional importance and the integration of this knowledge with parametric design methods to achieve new design solutions in façade design. The study then demonstrates the kinetic façade concept through a jali. Two design exercises have been carried out and their kinetic systems explored, with the potential of a simple geometric design used as a module to generate the skin and its kinetic response. The investigations from this research open a gateway for further explorations in jali design, using parametric tools to develop kinetic responsive skins.
\end{abstract}

Keywords

parametric patterns, parametric design, kinetic façade, kinetic jali, responsive skin

\section{Introduction}

Jali (Urdu word) is an architectural element found in the Indian subcontinent and Islamic architecture. A jali is an ornamental perforated screen that has been a significant architectural feature in Mughal architecture for decades. One of the major architectural elements commonly found in the region, jali designs were usually geometric patterns carved out on red sandstone or marble.

Geometrical shapes have been used for ornamentation purposes in Islamic art and architecture and as a unifying concept. It unifies the composition regardless of the diversity of materials and forms. These complex patterns are based on several features and principles, the foremost being symmetry, harmony and balance of proportions. The second major principle is the repetition of the unit, forming the basis of the geometric patterns. Later scalability, adaptability and coverage focus on the elements, materials and the object itself, whether a small vase or a wall. Movement, the illusion of continuity and framing of the patterns on pre-calculated surfaces are also significant aspects of these geometric patterns in Islamic art and architecture.

The Mughals artisans and architects used jalis not only as ornamentation but considered it as one of the primary architectural elements in a building's design. These intricate and highly crafted screens are remarkable decorative pieces of art and play a vital role in the ventilation of the building. They allow air to pass; simultaneously, they are very efficient in tempering sunlight and eliminating glare, making the interior spaces more comfortable. Jalis are also essential for privacy, particularly in the context of purdah (veil), acting as a buffer between inside and outside. Due to the contrast, the view of the outdoors or the street is possible, whereas the interior view is limited.

This paper aims to explore different strategies for Islamic geometric patterned screens, designed for kinetic 
facades, in response to the existing environmental conditions. This design process and research aim to explore possibilities for modern-day use of screens on existing structures or new designs. The following covers a research design methodology for this purpose:

1. Stage I: Preliminary literature review (goals and objectives). The main concepts of facades and their significance are understood by reviewing the related literature. The second stage is understanding passive cooling techniques with the significance of jalis identified through preliminary review literature. By understanding the responsive facades, Islamic geometric patterns and jalis, the relationship between the concepts is highlighted, and goals and objectives of the study are formulated.

2. Stage II: Literature review (setting up a theoretical framework). The second stage of the study, the literature review, covers the concepts, importance and relationship of the responsive facades and the patterns of screens through an examination of journals, reports, international case studies and online research. The in-depth review helped to formulate the theoretical framework of the study.

3. Stage III: Design Process; Amalgamation of screen and façade following the literature review covered in the context of case studies and formulating a better understanding, two design exercises are performed in order to explore the possibilities

4. Stage IV: Analysis and Recommendations; The last stage of the study, concludes the research, attempts to analyse the findings from the study of responsive facades using computer-aided design software against the backdrop of the literature review and theoretical framework. It presents potential areas for future research on jalis and kinetic facades.

The research concludes with the importance of understanding the merits of traditional/vernacular architectural elements for environmental and aesthetic purposes and their potentials for today's architectural design practices. In the case of this research, the significance of jalis as building elements is illustrated. The question of how they can be used efficiently in modern architectural practices for passive cooling techniques and design purposes is characterised to demonstrate the subject's significance.

\section{Literature review and theoretical framework}

Façade (a French word) is typically used for the elevation or exterior of the building (not only the front elevation, but since its literal meaning is face or frontage, it is taken as such). It has always been the interface between the building and the environment. Façades can be entrusted with multiple vital functions that dictate the building's energy consumption which determines indoor environmental quality (Loonen, 2010; Sharaidin, 2014). It holds great importance and is considered a significant aspect in architecture design, as it not only acts as the envelope of the interior spaces, it also holds aesthetic value and creates the image of the building, making it an icon or landmark.

Envelope is a generic term that describes the total enclosure of a building; a wall was traditionally used to describe a vertical load-bearing construction (Moloney, 2011). From an engineering aspect, it is the principal element of the building as it impacts the building's energy efficiency.

The concept of effective facades that adapt to environmental conditions dates back to when windows and ventilators were designed in response to the site conditions. In general, facades are designed to respond to many scenarios and perform functions that may contradict each other: daylighting versus energy efficiency, ventilation versus views and energy generation (Nady, 2017).

Over time, due to constant research and development, architectural tools and materials have evolved, resulting in major changes in façade design and structures. The very concept of modern architecture came into being at the moment that the domain of the 'building arts' began to be positioned, consciously and explicitly, in relation to the ideas of a modern society (Wagner, 1988; Avermaete, 2018). The Industrial Revolution marked an entirely new era in the construction world; the whole structural system and concept of façade changed, as load-bearing building structural frames were covered with non-load bearing façades. New materials and production methods opened up entirely new opportunities- iron and glass conquered architecture, the process of dissolving the skin - its de-materialisation - is directly linked to the progressive independence from its load-bearing function (Schittich, 2017). In the early twentieth century, Leatherbarrow and Mostafavi (2005), in their book, Surface Architecture, introduced the term curtain wall to distinguish between structural and non-structural elements of a building. This revolution gave birth to the skyscraper era, where the façade acted as a curtain wall hung over the structural frame (steel or concrete). Fig. 1 represents the brief history of the evolution of façades from the $19^{\text {th }}$ century onwards.

The term skin was initially coined to continue the distinction between cladding and the structural 'bones' of a wall but has more recently been associated with conceiving the envelope as an intelligent environmental system. 


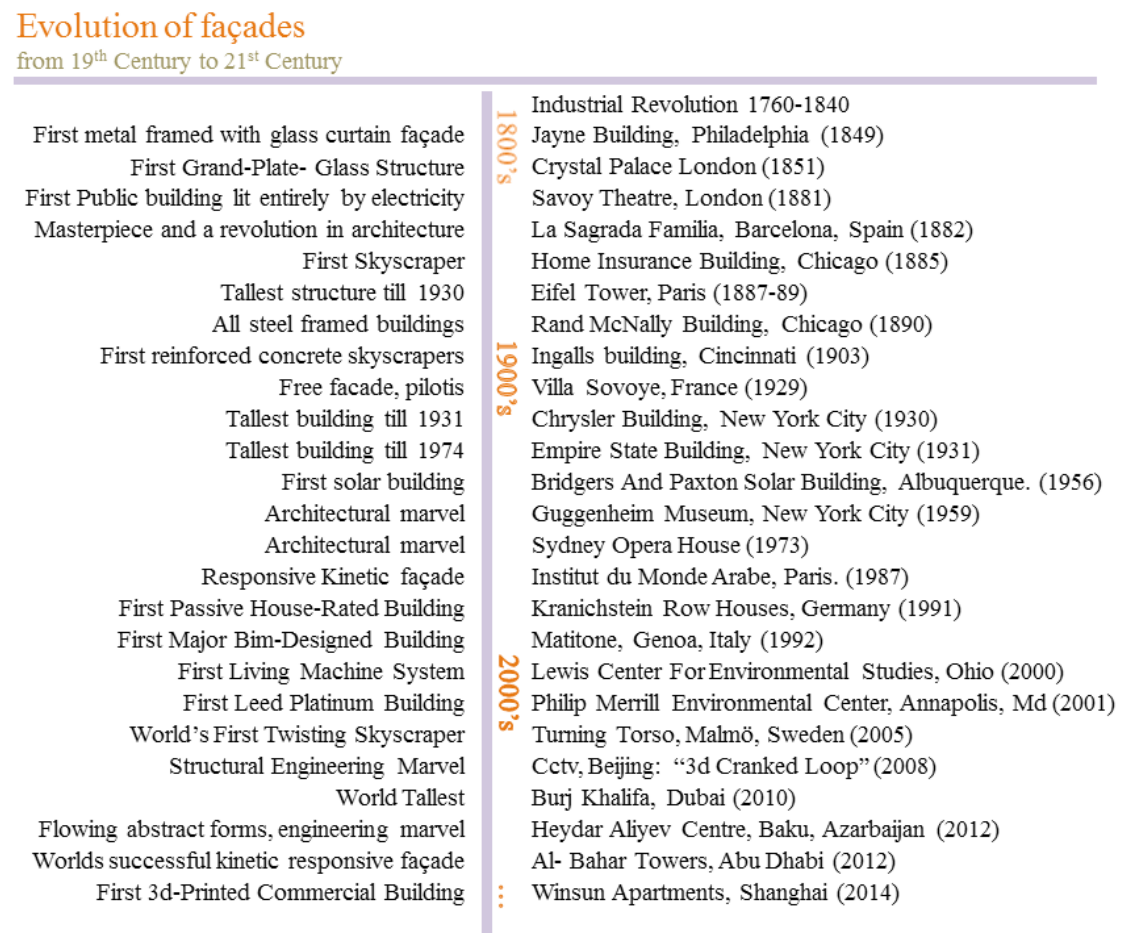

Fig. 1 Evolution of façades $19^{\text {th }}$ century $-21^{\text {st }}$ century (prepared by the authors)

At the same time, facade still retains an association with wall as the site of urban composition (Lupton et al., 2002). The building skin is the primary subsystem through which prevailing external conditions can be influenced and regulated to meet the user's comfort requirements inside the building (Lang, 2017). Today, the buildings skin or façades are not only building envelopes or an interface between inside and outside. It claims responsiveness to the place-specific character and a unique identity and privacy, transparency, energy efficiency, unbroken views, minimum glare, and materiality. It is continually asked to resolve a greatly expanded field of parameters in its performance. With the advancement in science and technology, the idea of a kinetic façade has also evolved. The recent advances in material, chemical science and parametric modeling tools act as major catalysts in the understanding and designing kinetic and responsive façades.

The concept of kinetics in the architectural design approach is not the new phenomenon as it seems. In the early 1970s, Zuk and Clark (1970) introduced the idea of kinetic architecture to contend with spatial design problems using mechanical systems. Although in mechanical engineering, understanding of the mechanisms and kinetics had started a long time ago. The works by the early scholars provided a basic understanding of kinetics and laid the foundation for several ideas for the implementation of kinetic façades. This research has been fruitful for the understanding and development of the design of the complex mechanism; there is no further work on the use or implementation of these kinetic compositions and mechanisms on building façades for creating responsive a kinetic façade. Fig. 2 represents a historical background on kinetics development on the theories of mechanisms used in mechanical engineering.

It is noteworthy that mechanical engineers helped develop the understanding of the kinetics and the sense

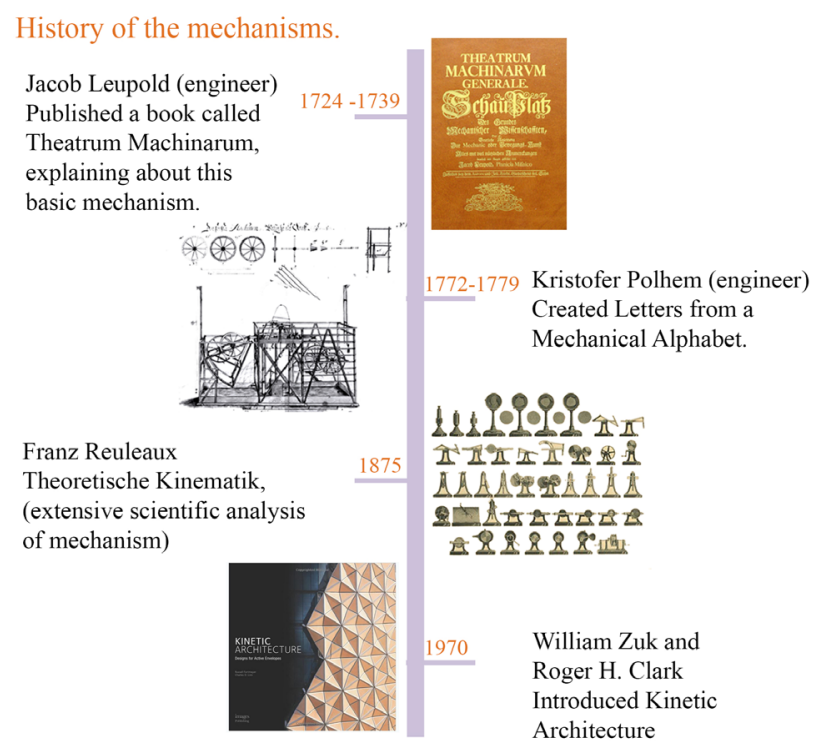

Fig. 2 Mechanical engineering to kinetic architecture (prepared by the authors) 
of motion and that artists played a major role. The kinetic sculptors completely changed the idea of art being static. Majorly intrigued and inspired by the natural environment, they explored materials and designed dynamic kinetic sculptures, which later inspired the development of the kinetic façades. Fig. 3 represents a brief description of the artists and their work, followed by Fig. 4, representing kinetic patterns in installations.

\subsection{Kinetic facades}

Today, the application of responsive elements in a building, such as kinetic facades, play an important part in a building's operation. However, the architectural design principles and construction methods of kinetic facades have been under explored (Park et al., 2011; Sharaidin, 2014). Kinetic façades are envelopes designed for high-performance buildings in response to environmental conditions and aesthetics. Wigginton and Harris (2002) define the intelligent skin as an active and responsive mediator between the outside environment and the interior of a building, which ensures an optimal interior comfort with minimal energy consumption (Böke et al., 2019). These

\section{Artists who played a significant role in the understanding of the kinetic movement}

Ruben Hyden Margolin (Kinetic Sculptor) demonstrate the ingenuity of kinetic composition that focuses on geometry and mechanical movements.

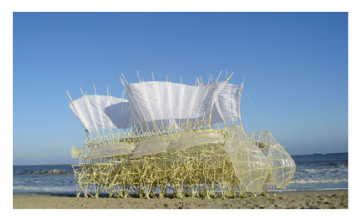

George Rickey (Kinetic Sculptor) successful kinetic works is the slow and graceful movements of Rickey's Counterweight
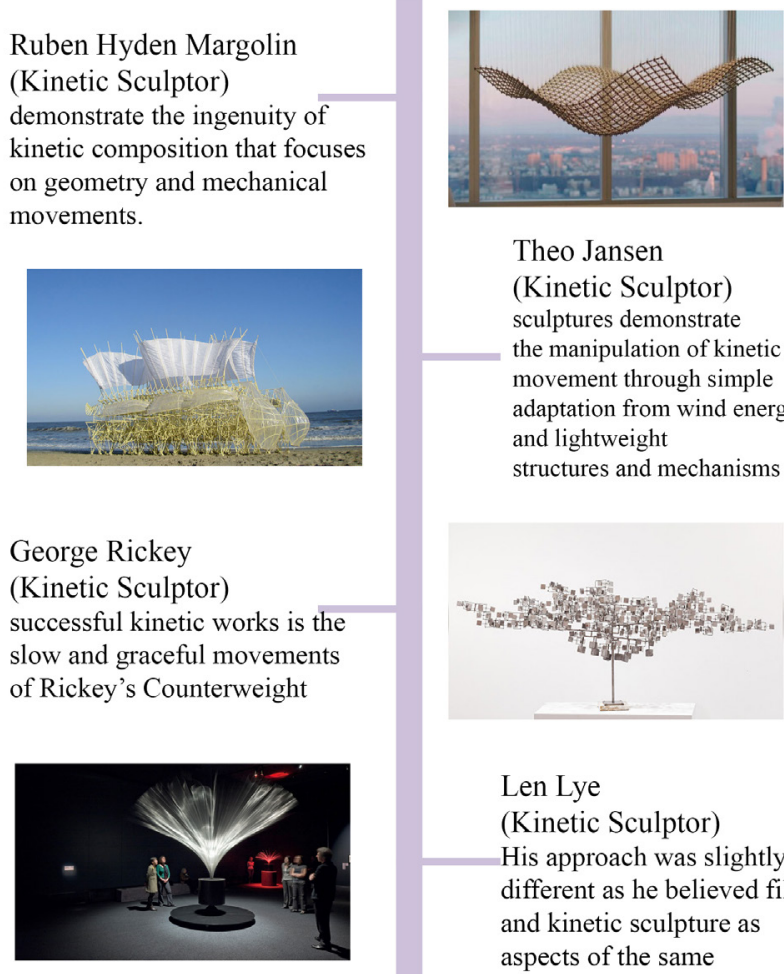

Theo Jansen (Kinetic Sculptor) sculptures demonstrate the manipulation of kinetic movement through simple adaptation from wind energy and lightweight structures and mechanisms

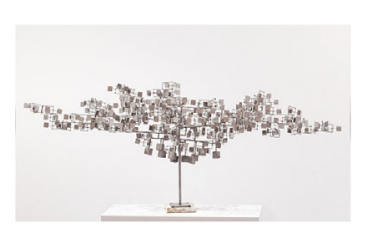

Len Lye

(Kinetic Sculptor) His approach was slightly different as he believed film and kinetic sculpture as aspects of the same "art of motion",

Fig. 3 Examples of kinetic sculptors and their significant contributions in kinetic compositions (prepared by the authors)

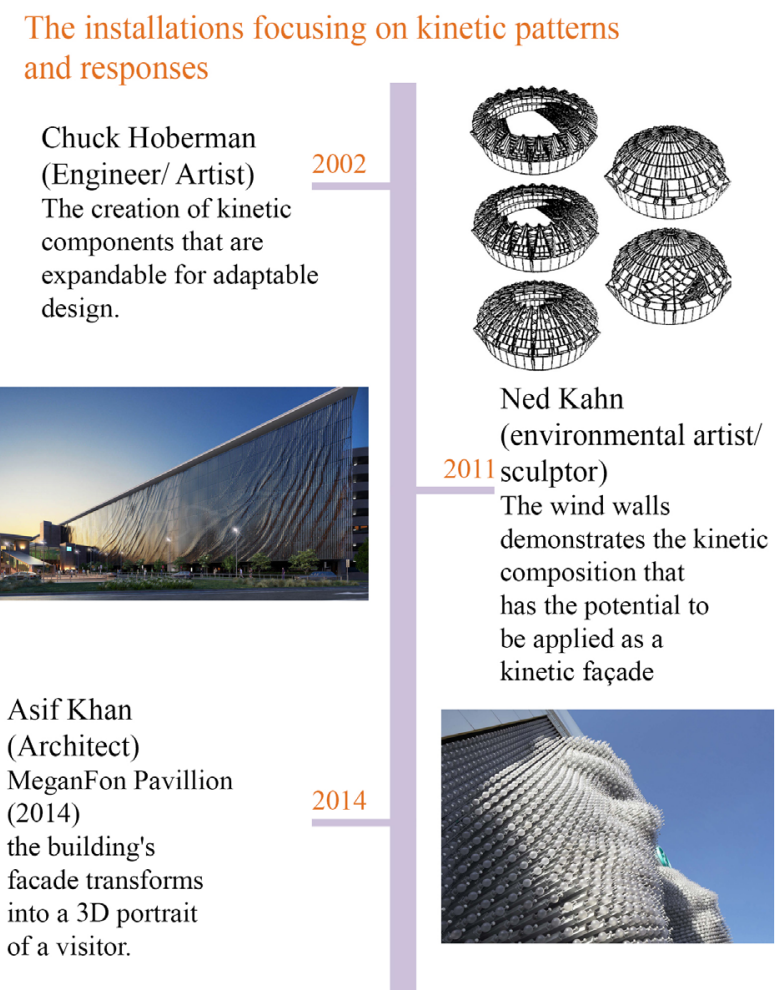

Fig. 4 Examples of responsive kinetic patterns used in installations (prepared by the authors)

facades are designed with actual motion, through geometric transformation, affecting the physical structure or material properties of the façade only, retaining the structural integrity. Kinetic facades offer new compositional opportunities based on the design of patterns of movement; kinetics is conceived as a state change. The terms used to describe states are wave, fold, and field; a full range of patterns can be described as variants of these three simple states; or intermediate or compound state transitions. (Moloney, 2009).

In today's growing technological advancement in every aspect of life, architectural design practice and its execution have also advanced. Contemporary materials and technological achievement give a variety of shapes and new possibilities in creating structural forms (Stolarewicz, 2012). Building envelopes tend to be smarter with more moving parts, and the primary trend driven by kinetic envelopes is sustainability and indoor comfort (Sullivan, 2006; Alhadi, 2011). In kinetic architectural designs, the architect's approach and requirements of every project vary, depending on the user, surrounding and the building type. Responsive building kinematics takes mechanical forces and principles of motion to change the size, form, or composition of a whole building or its parts (Yi et al., 2019). The architectural examples, to name a few that have 
revolutionised the façade design from being a static curtain to a living/ breathing skin, are stated in Fig. 5.

Responsive facades functions and requirements vary from location to location, as the main objective is to achieve an environmentally responsive facade for maximum efficiency and energy conservation. Every region has its challenges when it comes to design problems. However, the most challenging are the designs for hot arid climate regions. In these regions, buildings require more energy, especially if it is a high-rise building, for cooling and thermal comfort, making the facades the most vital part of the design not only for its aesthetic appeal but also its practical aspects as a membrane covering the building and accommodating efficient thermal performance. Institut du Monde Arabe in Paris, Al-Bahar Towers in Abu Dhabi and Simons Centre at Stony Brook University in New York, are pioneering examples of responsive facades designed for specific site conditions and situated in different contexts using geometry inspired by the Arabs.

In Institut du Monde Arabe in Paris, Jean Nouvel took inspiration from the Arab mashrabiya's and geometry to design the south façade, with photoelectric cells and mobile apertures mechanism that performs a maximum of eighteen

\section{Kinetic façades}

Richard Neutra (Architect)

LA County Hall of Records (responsive brise-soleil)
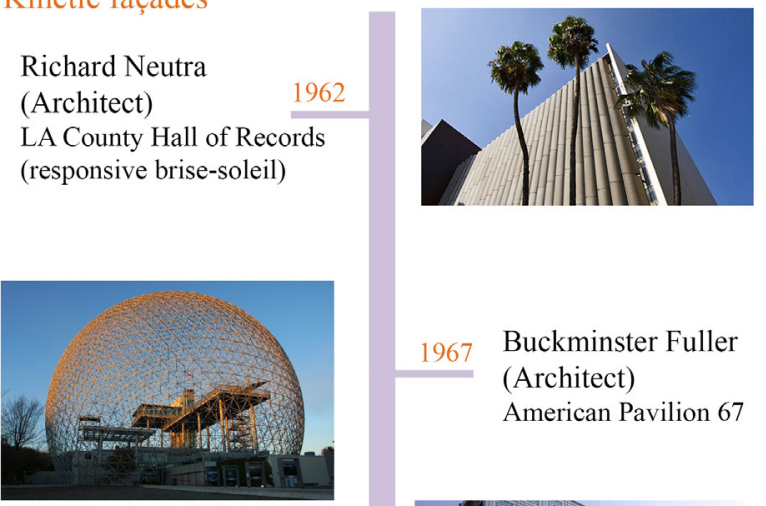

967

Buckminster Fuller (Architect)

American Pavilion 67

Jean Nouvel

(Architect)

Institut du Monde Arabe,

Paris
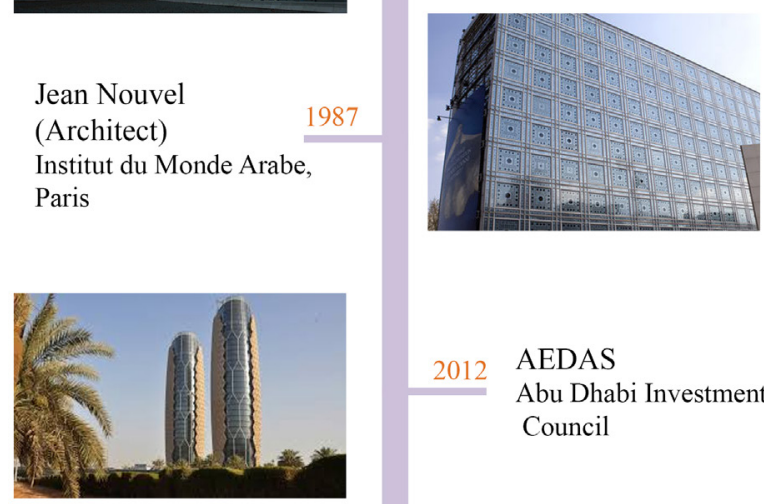

AEDAS

Abu Dhabi Investment Council

Fig. 5 Examples of kinetic façades, responsive to the surrounding environment (prepared by the author) movements to control and allow natural light. On the other hand, in Al-Bahar Towers, we find the concept of the mashrabiyas with geometric patterns fused with the kinetic mechanism inspired by nature, the opening and closing of flowers in response to the sun. Another remarkable example of the kinetic screen is Simons Centre at Stony Brook University, an architectural marvel by Chuck Hoberman and Perkins Eastman. The screen is designed with four layers of perforated stainless steel panels; three of the panels are motorised layers of geometric panels that respond to temperature change. The effect of the screen resembles a flower, and the tessellation appears as if blossoming into a burst of geometric patterns - hexagons, circles, squares and triangles, resulting in an opaque mesh, but when the patterns are aligned, they allow maximum light, as shown in Fig. 6. The outcome is a kinetic pattern that spreads 124 square
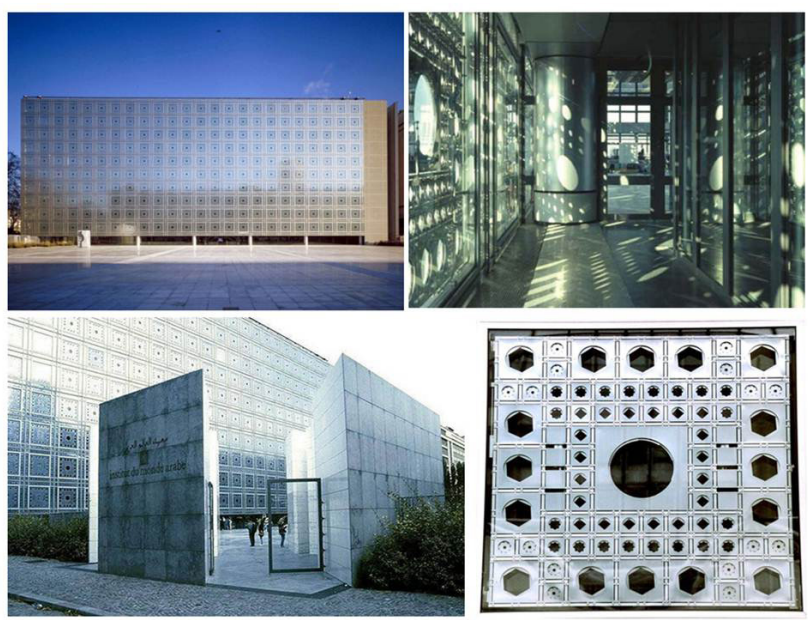

(a)

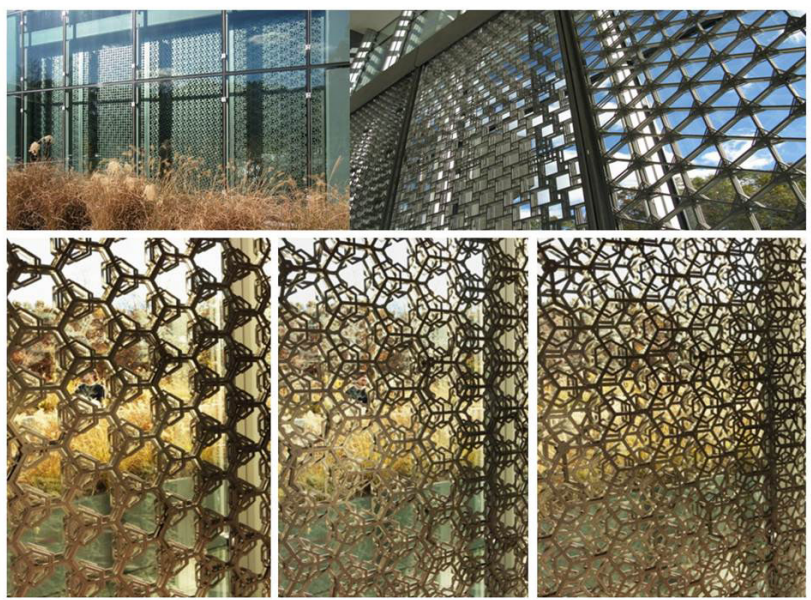

(b)

Fig. 6 Kinetic facades (a) Institut du Monde Arabe, Jean Nouvel (Michler, 2010); (b) Simons Centre, Stony Brook University in New York (Hoberman, 2010). 
meters and provides the building with the functional capability to a dynamic opacity transformation (Hoberman and Schwitter, 2008; Alkhayyat, 2013)

The parametric design and kinetic façades have brought a drastic change in the mindset of architects and designers, as there is a shift from the conventional problem solving in a defined formal solution to an entirely new dimension where countless possible outcomes are using advanced computational techniques. Generative design systems allow the formulation of complicated compositions, whether formal or conceptual, through an application for a simple series of equations and parameters. This new definition marks the development of innovative methods of design thinking (Alkhayyat, 2013).

Parametric geometry modeling is a field studying algorithms that compute geometry (Kelly, 2013). Since the release of new parametric software like Generative Components or Grasshopper, the conceptual representation containing the algorithms can be achieved through visual dataflow programming language (VDPL) dedicated to 3D modeling (Gallas et al., 2015).

The objective of integrating computers as tools for the design process is the potential for the conscious exploration of the elements that define a computable function as design tools. Therefore, digital design is about the interaction of formal processes with architectural thinking (Makert and Alves, 2016). Today, in architectural design, the kinetic façade is the new present and the coming future of the façades. It is constantly progressing and putting forward new challenges, addressing new problems and finding new solutions.

\subsection{Design inspirations and process}

Jali (net/web), also referred to as screens, have been amongst the significant features of many architectural marvels found in the Indian subcontinent. In Mughal architecture, the jali was an ornamental perforated screen and played a significant role in buildings' passive design strategies, tackling the natural light and ventilation and the quality of retaining privacy, acting as a buffer between interiors and exterior.

Jalis were used as windows or interior room dividers, allowing light and air to enter the room while screening the inhabitants from the glare of the sun and the gazes of passersby (Ekhtiar and Moore, 2012). Figs. 7 to 9 show a pavilion in the Lahore Fort Complex, Deewan-e-Khaas, a marble pavilion for private audiences in Shahjehan's Quadrangle. This pavilion has intricately carved screens, used in multiple ways, and arches with different geometric patterns.

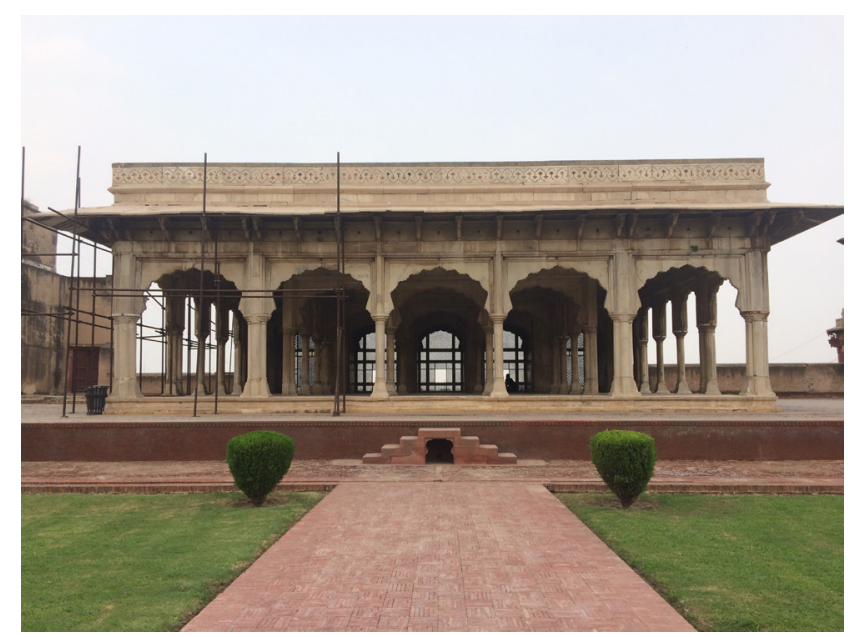

Fig. 7 Deewan-e-Khaas (Hall of Private Audiences), Lahore Fort Complex, Shahjehan's Quadrangle (photo by the author, 2019)

The use of screens or jalis has been observed in the architecture of many regions due to the functional aspect of passive cooling and its aesthetic value. They can be seen in various architectural marvels worldwide, built by the different dynasties and empires.

Due to diverse environmental conditions and context, we see different uses, materials, techniques, patterns and jali designs. Passive cooling refers to any technologies or design features adopted to reduce the temperature of buildings without the need for power consumption (Taleb, 2014). There are four main approaches or methods for passive cooling in order to achieve thermal comfort. These elements are basic yet crucial in designing passive cooling techniques and include envelope design, natural cooling sources, hybrid cooling systems, and adapting lifestyle (Okba, 2005). The first and foremost is the envelope design. As the façade covers the whole building, it is vital to consider the form and material of this layer to achieve maximum results in energy consumption and heat gain.

\subsection{Jali design in the Lahore Fort Complex as a medium to analyse geometric pattern tessellation in Mughal architecture}

In Mughal architecture, geometry was significant in planning and ornamentation and designing various architectural elements such as fountains, water bodies, windows, ceilings, floor finishing, railings, mosaics and jali(screen). Jalis are one of the multifunctional architectural elements incorporated in window frames and arched entrances, balconies, and jharokhas (ornate bay windows used by the emperors to address the public), with different geometrical patterns and tessellations. Two of the Mughal era's 


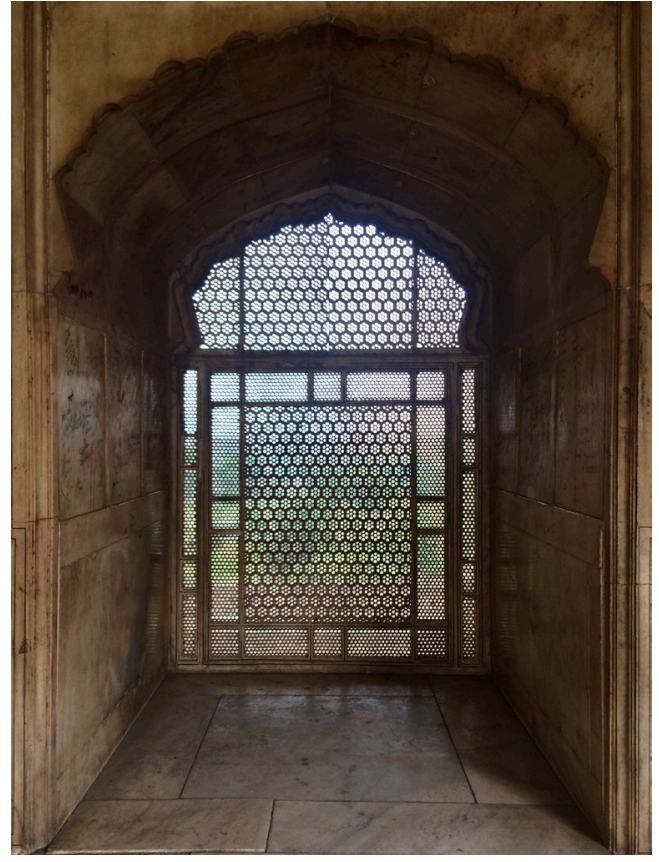

(a)

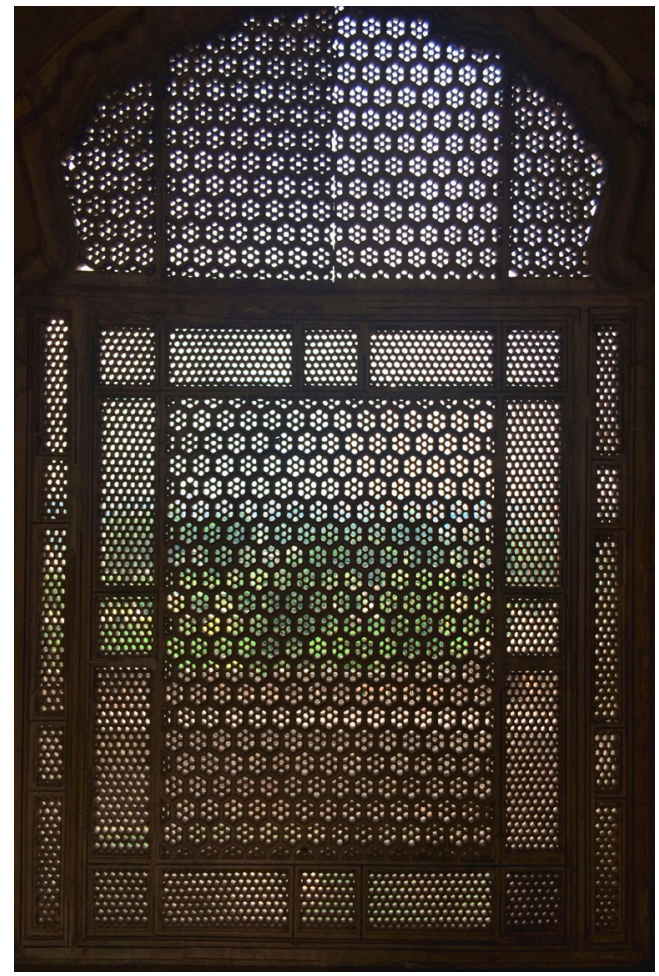

(b)

Fig. 8 Deewan-e-Khaas (Hall of Private Audiences), Lahore Fort Complex, Shahjehan's Quadrangle (2019). Use of screens in windows and entrance (photos by the author, 2019)

architectural marvels that represent the remarkable craftsmanship and use of geometry in ornamentation in various elements are the Taj Mahal in Agra and the Lahore

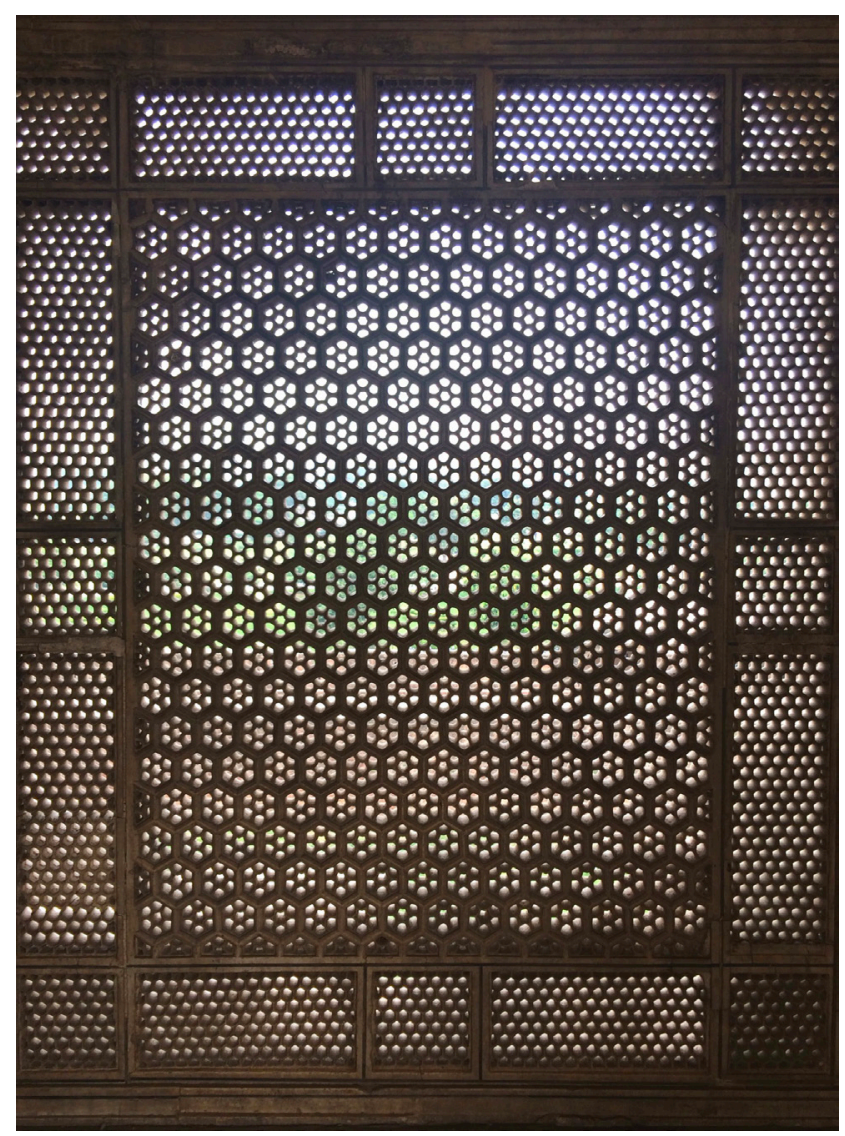

Fig. 9 Deewan-e-Khaas (Hall of Private Audiences), Lahore Fort Complex, Shahjehan's Quadrangle (2019). The screen on the exterior (northern) façade of the pavilion for privacy, view and ventilation. (photo by the author, 2019)

Fort Complex. The Mughal artisans and architects' area of focus was on geometric proportion, angles and tessellations; as a result of which, this period displays the finest examples of designs with 6,8,10 and 12-point patterns over sandstone and marble (Reki and Selçuk, 2018).

The Naulakha Pavillion is an excellent example. A summer pavilion designed for the Mughal Emperor Shahjehan as a personal chamber. Located in the Lahore Fort Complex's northern section, the pavilion is considered a masterpiece due to the remarkable architectural features it displays, the thinness of the curvilinear roof, the jalis, and the joint free marble structure itself. The exterior western side of the pavilion, designed to frame the Ravi River and the green forests beyond, has intricately carved marble jali. This pavilion is considered amongst the finest ornamented pavilions in delicate 'parchin kari' (pietra dura). Fig. 10 shows the front elevation for the pavilion and the jali details.

Inspired by the jali in Mughal architecture and geometric patterns, the study aims to use the findings from the literature review and use it to develop a skin using parametric 


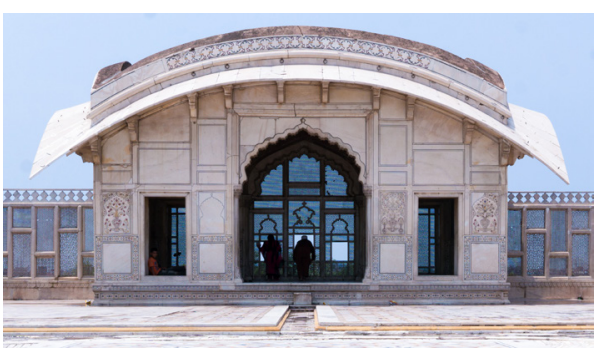

(a)

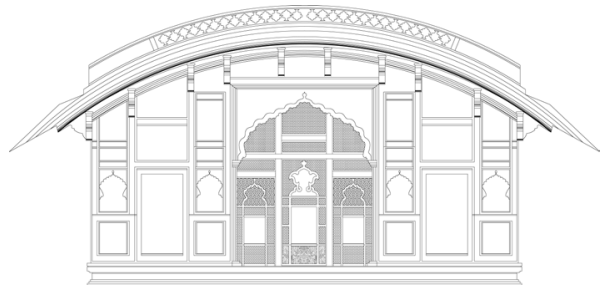

(b)

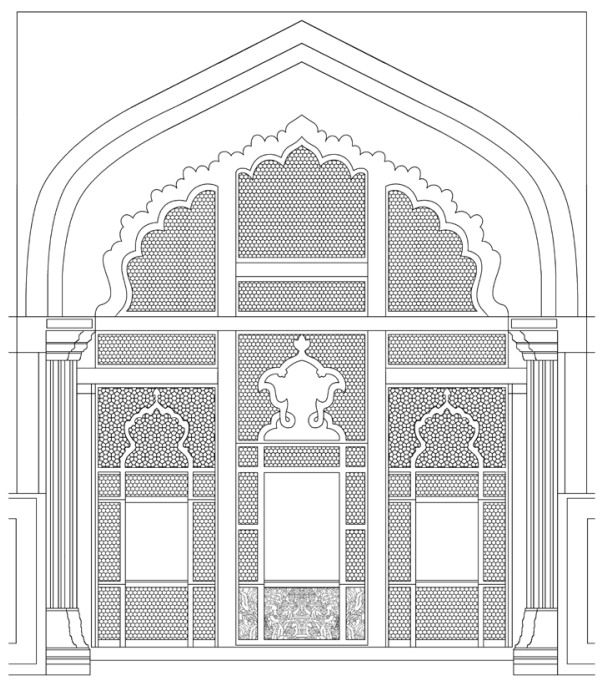

(c)
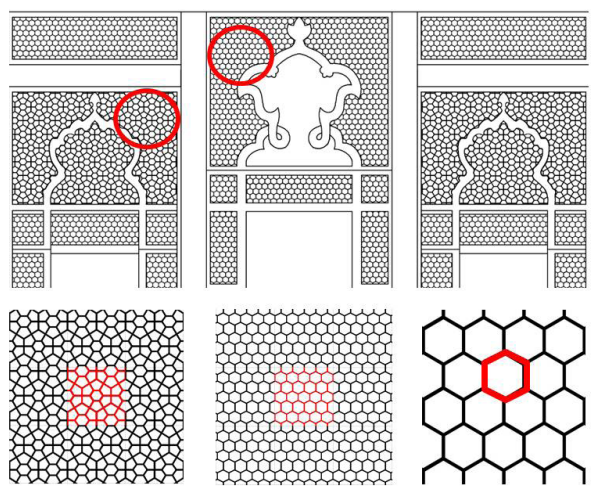

(d)

Fig. 10 The Naulakha Pavilion in the Lahore Fort Complex (Hassan, 2014). The pavilion's central arch drawing and details, showing the intricate geometric (hexagonal) pattern tessellation carved from white marble. Drawn by authors. (Reki and Selçuk, 2018) design. The central concept of this aspect is to design a kinetic skin for facades or screens that are responsive to sunlight and movement. The aim is to diffuse and control the direct sun's rays from open spaces like balconies and windows. The developed screen can also act as the second skin of the façade, behaving as a shield between the façade and the environment.

A hexagon is taken as a basic pattern, and it is used to develop the screen tessellation since it is a widespread jali design in Mughal architecture. Using Grasshopper as a parametric design tool, only two options are explored using the same basic geometric pattern. As we know, the possibilities are infinite with digital tools, and the designer has to set their boundaries and restrictions themselves. In this research, only two pattern tessellations are explored using the basic pattern for a better understanding and comparison. The process is kept simple in order to explore the idea and hope to open other doors for future exploration and design development.

3 Parametric design for kinetic façades using a hexagon as a basic design unit to develop a screen or a second skin for the façade

\subsection{Pattern design-1}

A hexagon grid is introduced (Fig. 11(a)) with a spline as the boundary that trims the grid. After removing the open cells outside the boundary, PCEN component is used to calculate polygon centers of the remaining cells (Fig. 11(b)). This spline can be taken as the area required for the screen and can be of any size. The offset of the hexagon grid and a planer surface is created connecting the two grids, creating a tube with a hexagonal base (Figs. 12 and 13). A point attractor is then introduced as an input parameter. The point attracter can be considered as any of the factors, be it physical or social. This attractor affects the offset of the inner hexagon, hence changing the aperture of the opening as it moves, as observed in Fig. 14. For instance, if sunlight is considered as the opposing factor and shaded area as the point attractor, the hexagonal cells will respond according to the attractor. The cells closer to the point attractor will be wider and allow more light/view/wind to pass through. In contrast, the other cells away from the point attractor have narrower openings to minimise the light from entering the interior spaces and minimise heat gain, as shown in Figs. 15 and 16.

As a result, this grid's base is static, but the design is effective in controlling the apertures. Material with expanding and contracting properties will be required, 


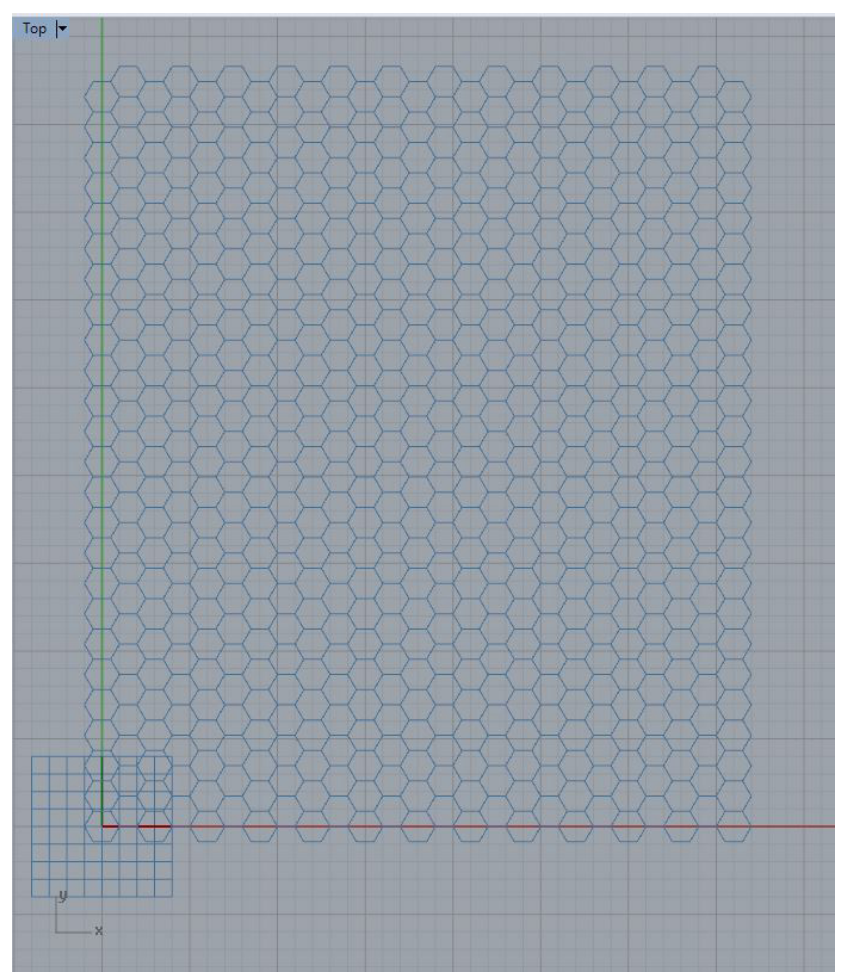

(a)

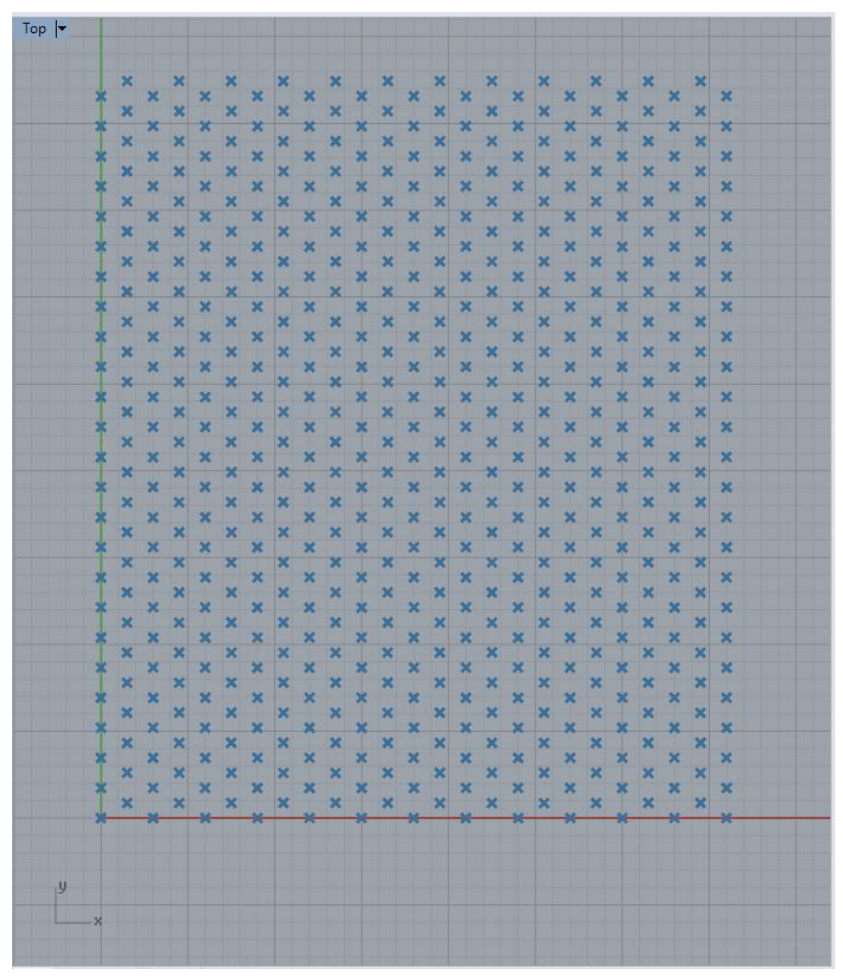

(b)

Fig. 11 The process (a)starts with a hexagon grid by using Hexagrid component; (b) PCEN component is used to calculate polygon centers of the remaining cells.

along with a hydraulic system to control the expansion and contraction of the opening.

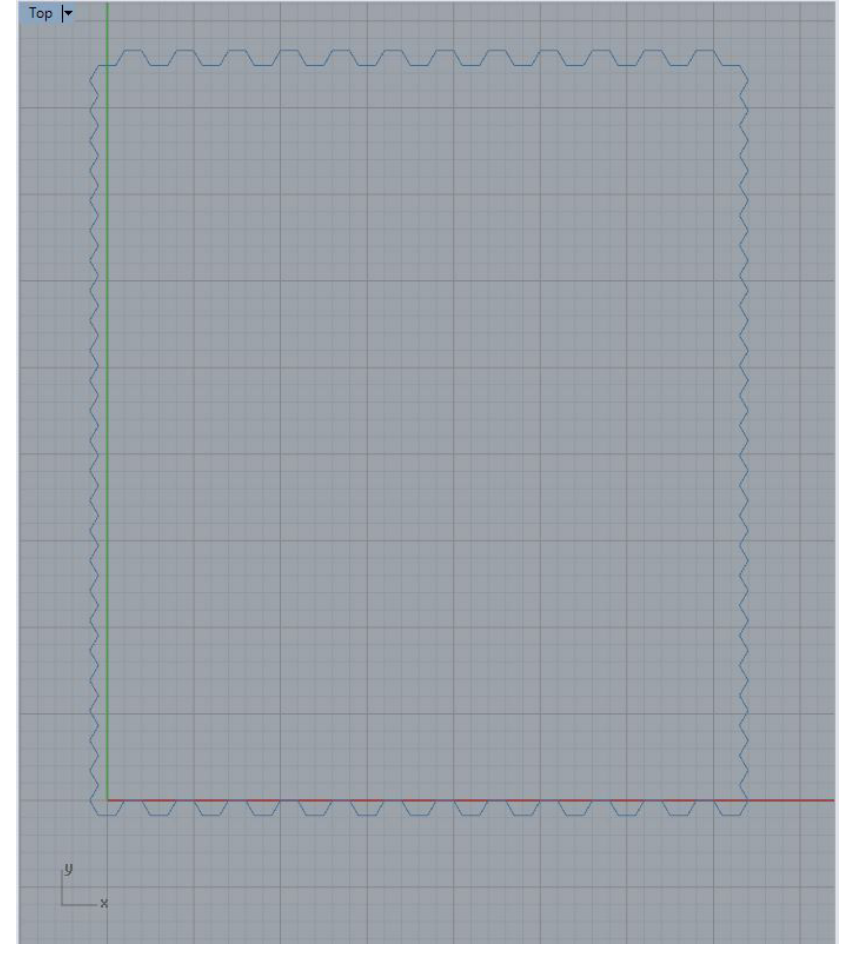

(a)

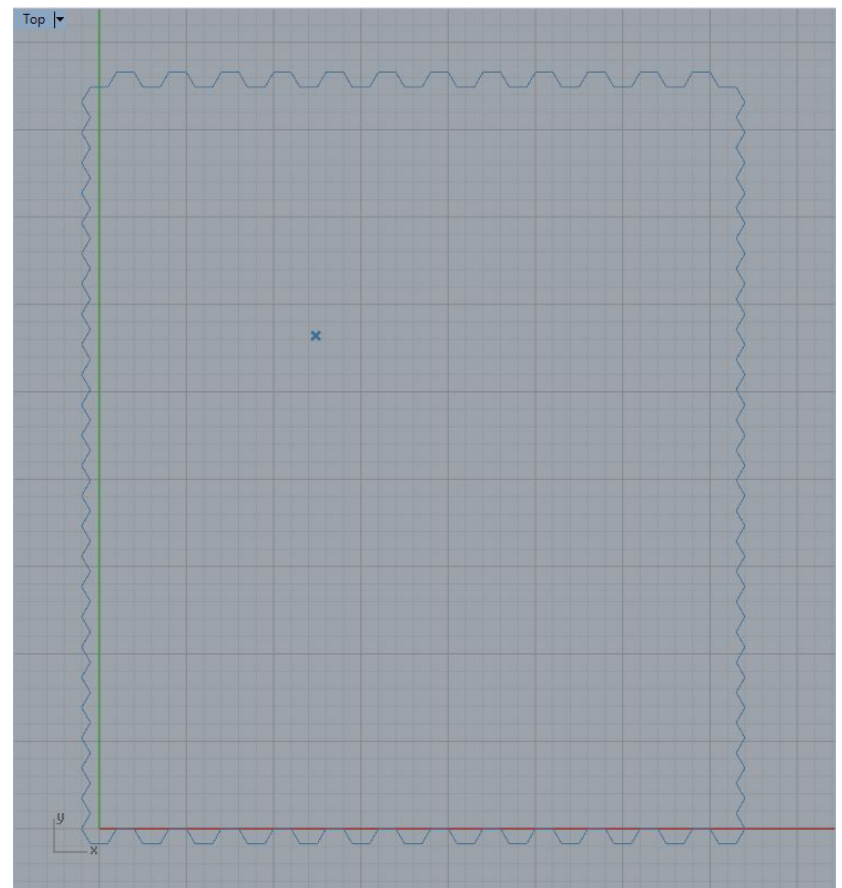

(b)

Fig. 12 The hexagon grid (a) Outline of the cells generated; (b) The component pull used to pull the input point

\subsection{Pattern design-2}

A hexagon grid was introduced, Figs. 17 and 18, which is used to extract edge vertices of its cells. A curve is also introduced in Rhino as an attractor curve, which will serve 


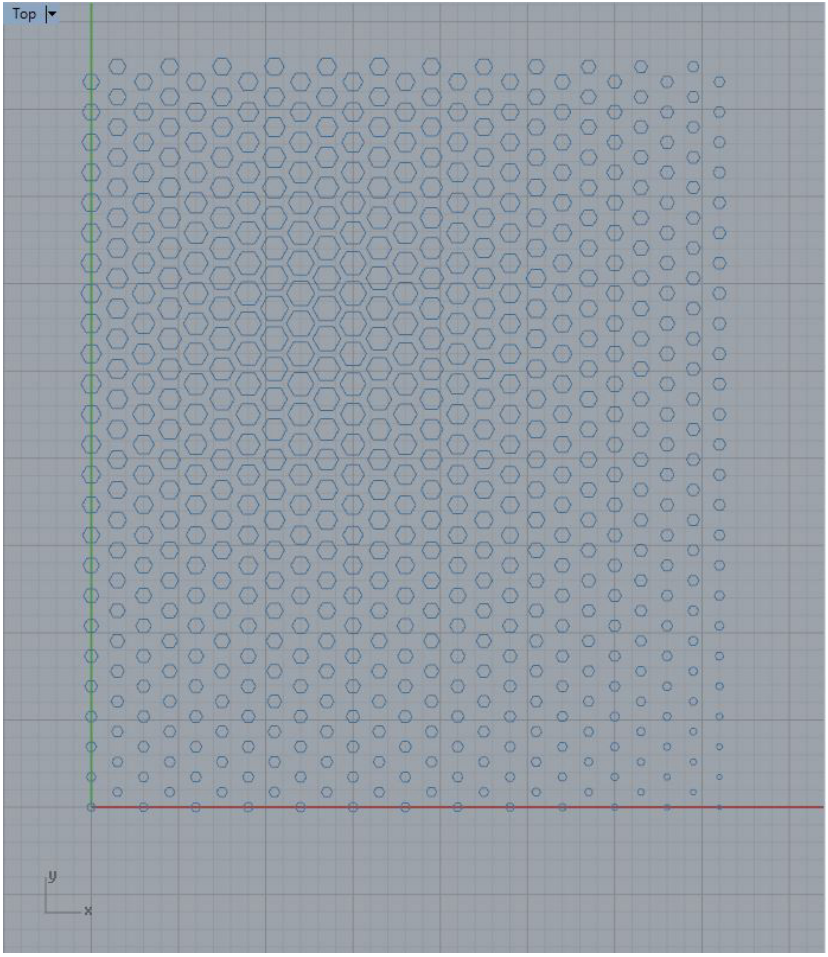

(a)

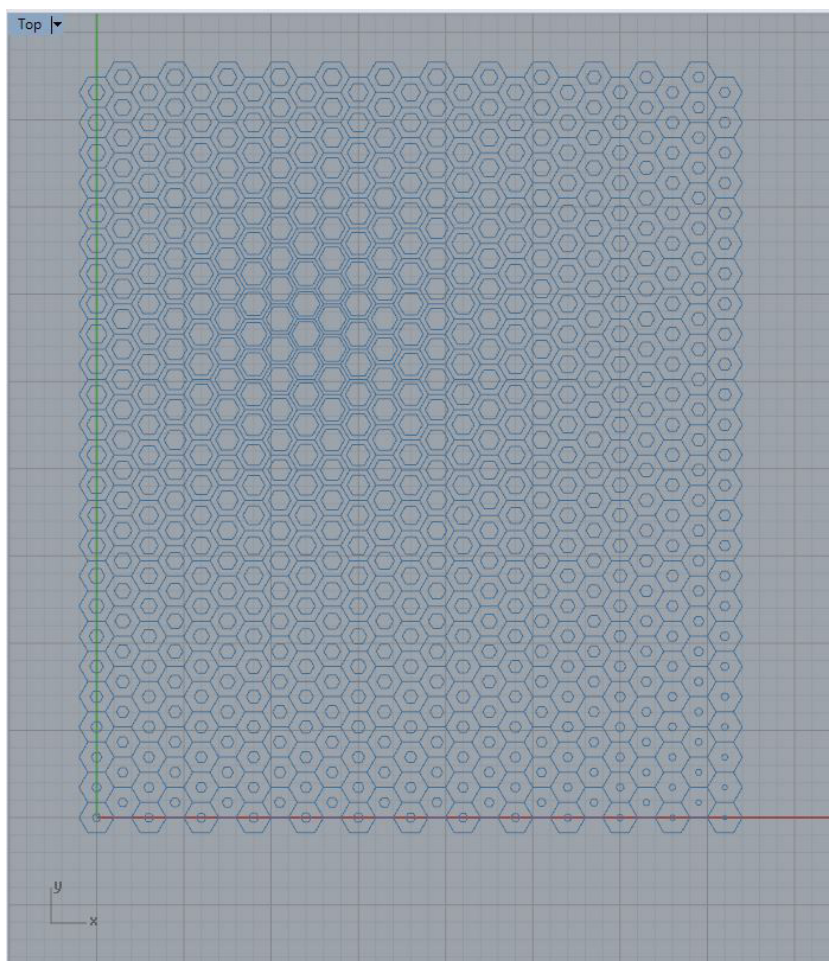

(b)

Fig. 13 The hexagonal grid (a) the scale factor to the cells creating an offset, based on the distance from the input point; (b) The two lists of cells are merged, putting corresponding cells in one branch of the tree to be lofted

as the source of our input. The input can be based on the architects' requirements, depending on which factor will be

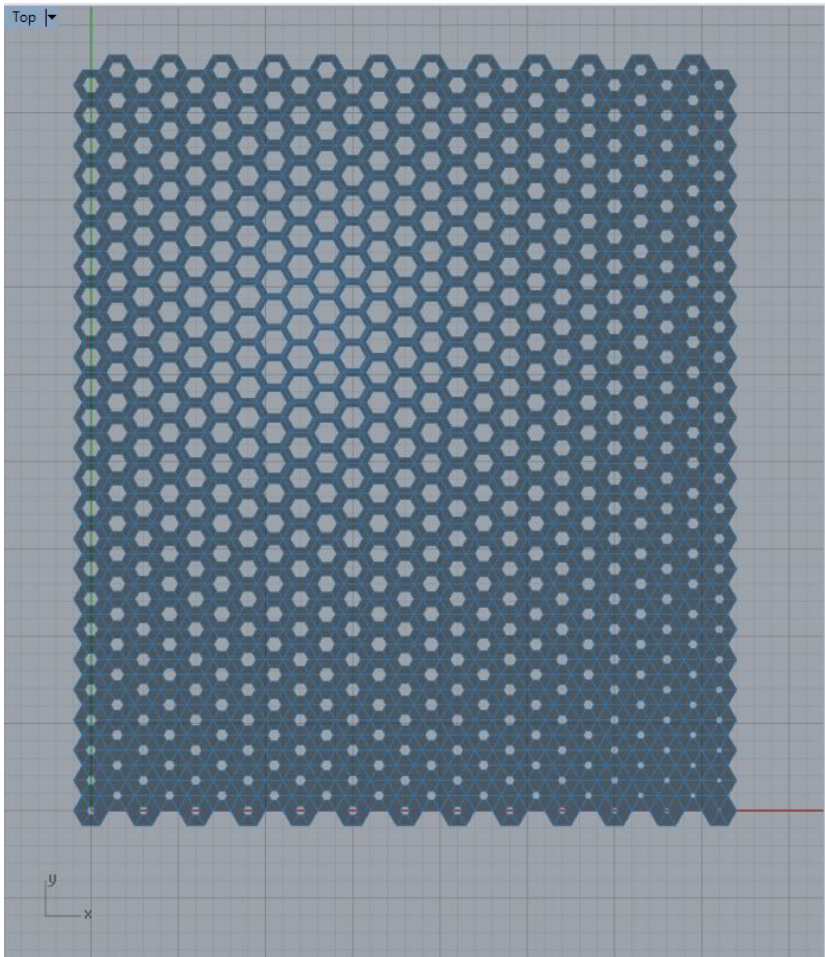

Fig. 14 The lofted two versions of the cell to create the module, which opens as it gets close to the input curve

considered the focal point; here, the two significant factors are solar exposure and privacy. Solar exposure suggests that the screen will be responsive to sunlight to avoid direct light and heat entering the interior spaces or the façade. On the other hand, the other major factor taken into consideration is privacy. As privacy is one of the significant elements of a screen, the inputs for this factor respond to the users' requirements and interaction. The screen's response, in this case, is directly responsive to the user providing them privacy without obstructing the views.

A set of points closest to the curve is generated through the interaction of these curves and points. These will become the basis for calculating the distance of the module from the attractor curve and its effect on it.

A set of points is generated along each cell to create a basis for the module modified as per its intensity calculated from the distance from the attractor curve. For the rotation, the same range domains have been made, which are affected by the distance of the cell from the closest point in the attractor curve, whose value is then fed into the module.

Once all the forces have been calculated and applied to the module's vertices, a polyline is generated to create outlines of the individual module, and then a planar surface is applied to the closed polyline curve to form an opaque object. A colour gradient module is then introduced to display the intensity of effect of the attractor curve on each 


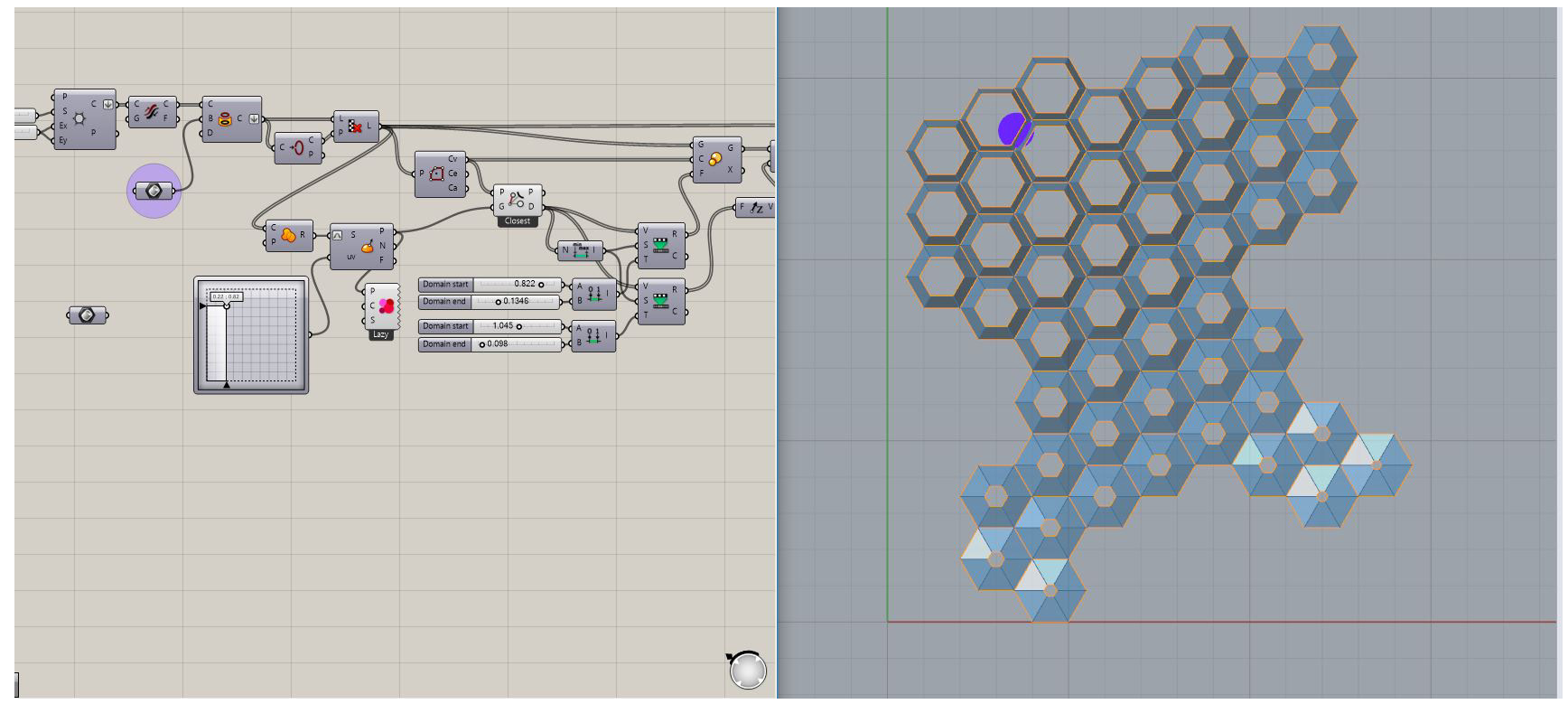

(a)

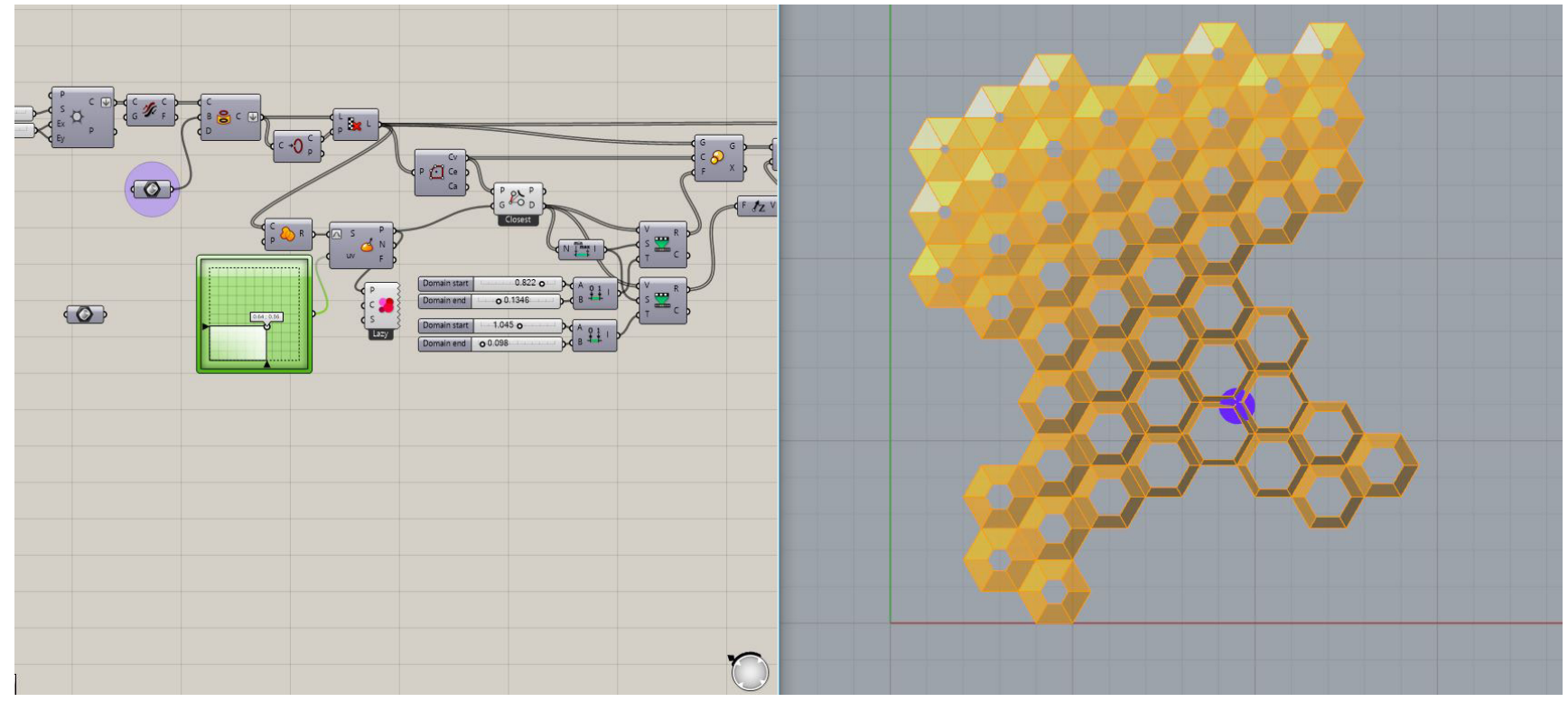

(b)

Fig. 15 The hexagonal grid with a point attractor; (a) ; (b)

module, creating a field. This process is repeated for the next layer of the screen, but here the effect of rotation is kept to zero to keep the grid intact and not lose its structural integrity. The script generates a field of module, initially without any rotation at their original state, retaining the hexagonal grid formation. The modules start evolving once the attractor is introduced as shown in Figs. 19 and 20. The transformation can be observed in Fig. 21.

As shown in Fig. 22, following an interaction with the introduced parameter observed in the Fig. 23, the grid of modules react, and the modules rotate based on the distance from the curve. The distance from the curve, in this case, is directly proportional to the rotation of the module. The gradient in colour shows the effect of the added parameter curve on the field. Its intensity increases from red to green. The amplitude of the joints of the star module is then connected to the distance of the module with the parameter curve. Hence, the closer the module is to the curve, the thicker it gets and opens up as it moves away from the curve, as observed in Fig. 22. As an extension of the adaption, another layer is introduced to the modules as an interaction with the parameter curve as shown in Figs. 24 and 25. In Fig. 26 we can observe the close-up of the two overlapped grids. 


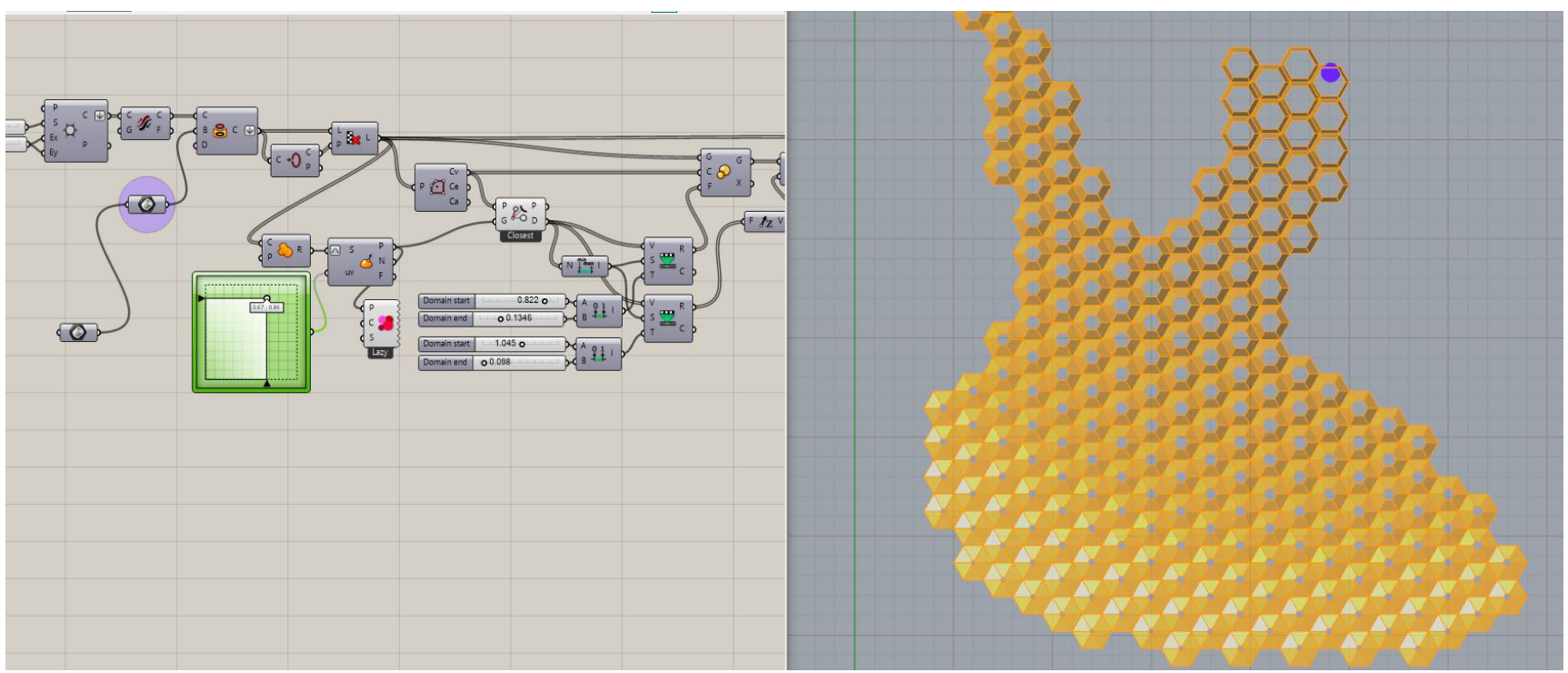

(a)

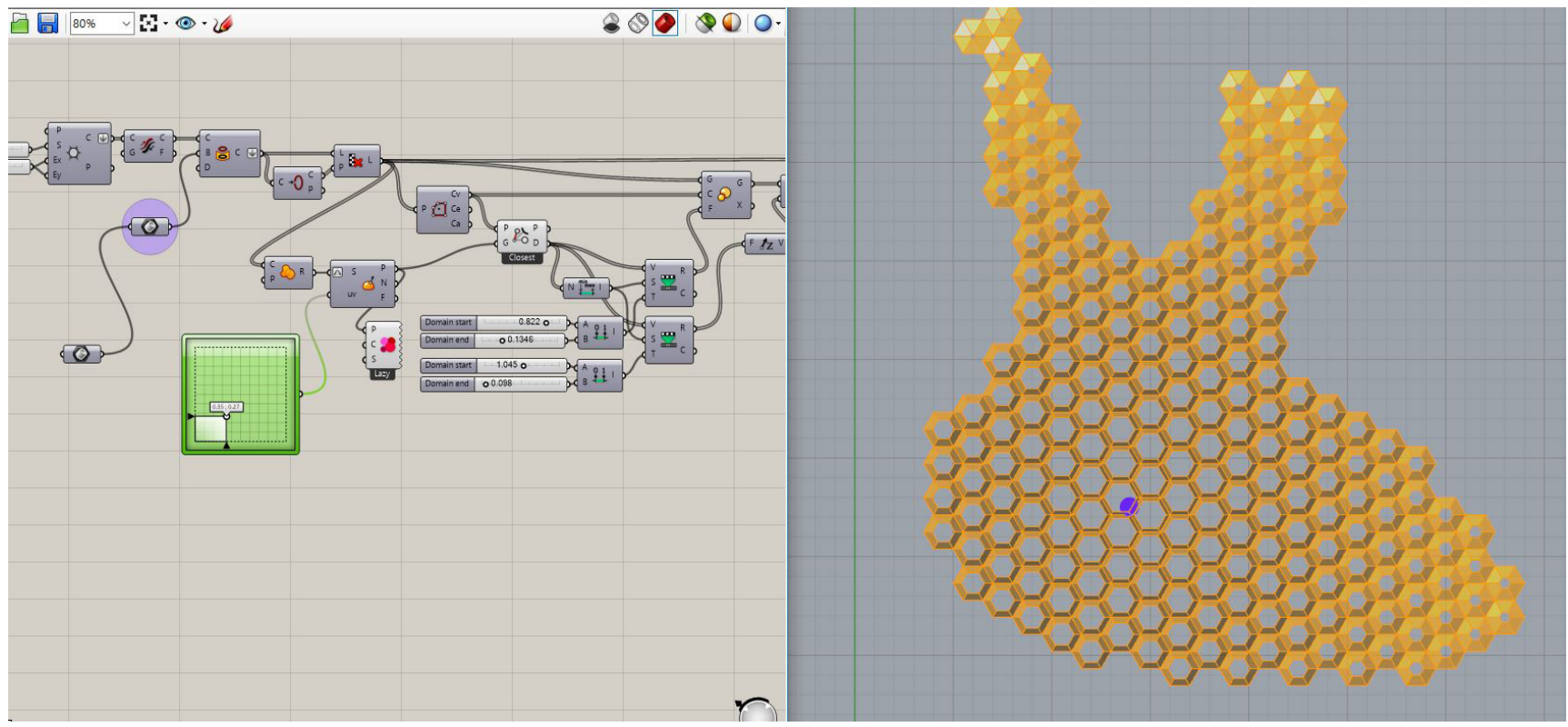

(b)

Fig. 16 The widening and contracting of the apertures as the point attractor moves around; (a) ; (b)

The result is observed in Figs. 27 and 28, showing the changed amplitude of vectors as per the distance of the input curve. Then these vectors are used to move our points to create an outline of each module; each affected the amplitude calculated from the input curve.

\subsection{Design drawings: the three layered jali}

In this design exercise, a hexagon is used as a basic unit, and it is broken into four parts; each part is a three-cornered star/ fan-shaped form, which is a single module with its pivot point. These modules rotate on their pivot point and also expand. The two parameters responsible for the expansion and contraction of response and the kinetic motion of this form are light/heat and motion. The screen is designed in three layers. The script controls their movement and can be programmed as required. The first is the lattice structure, a hexagonal grid. This is the static frame that acts as the base of the entire screen. (Fig. 29)

As shown in Fig. 30(a), the second layer is the kinetic translucent modules parameters, defined by the privacy, which is user interactive, as its rotation is based on motion sensors. This layer can be sensory based and scripted to respond to movement; as a result, it is a user-interactive screen. This layer is for privacy and view control. As the 


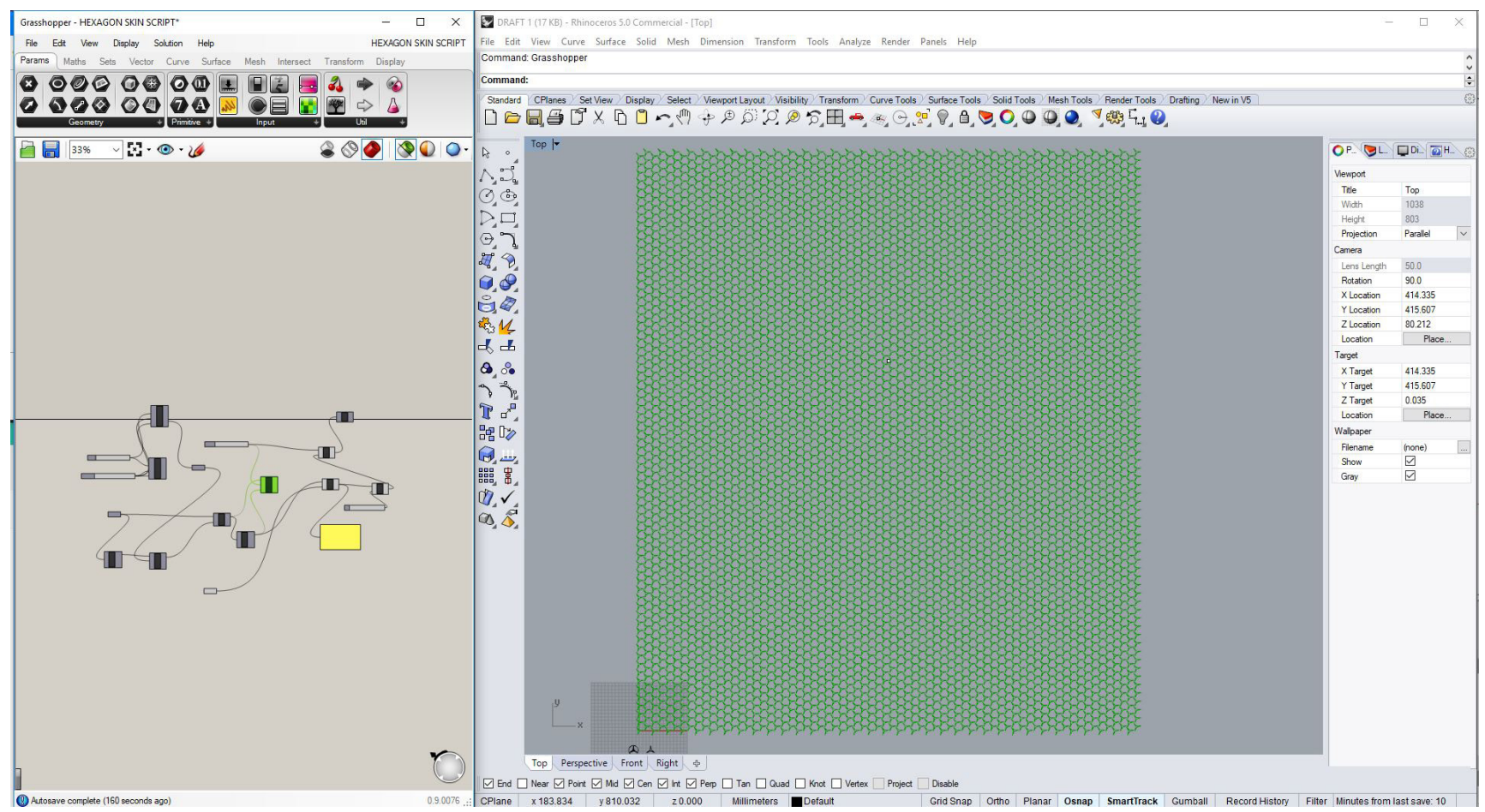

Fig. 17 The hexagonal grid

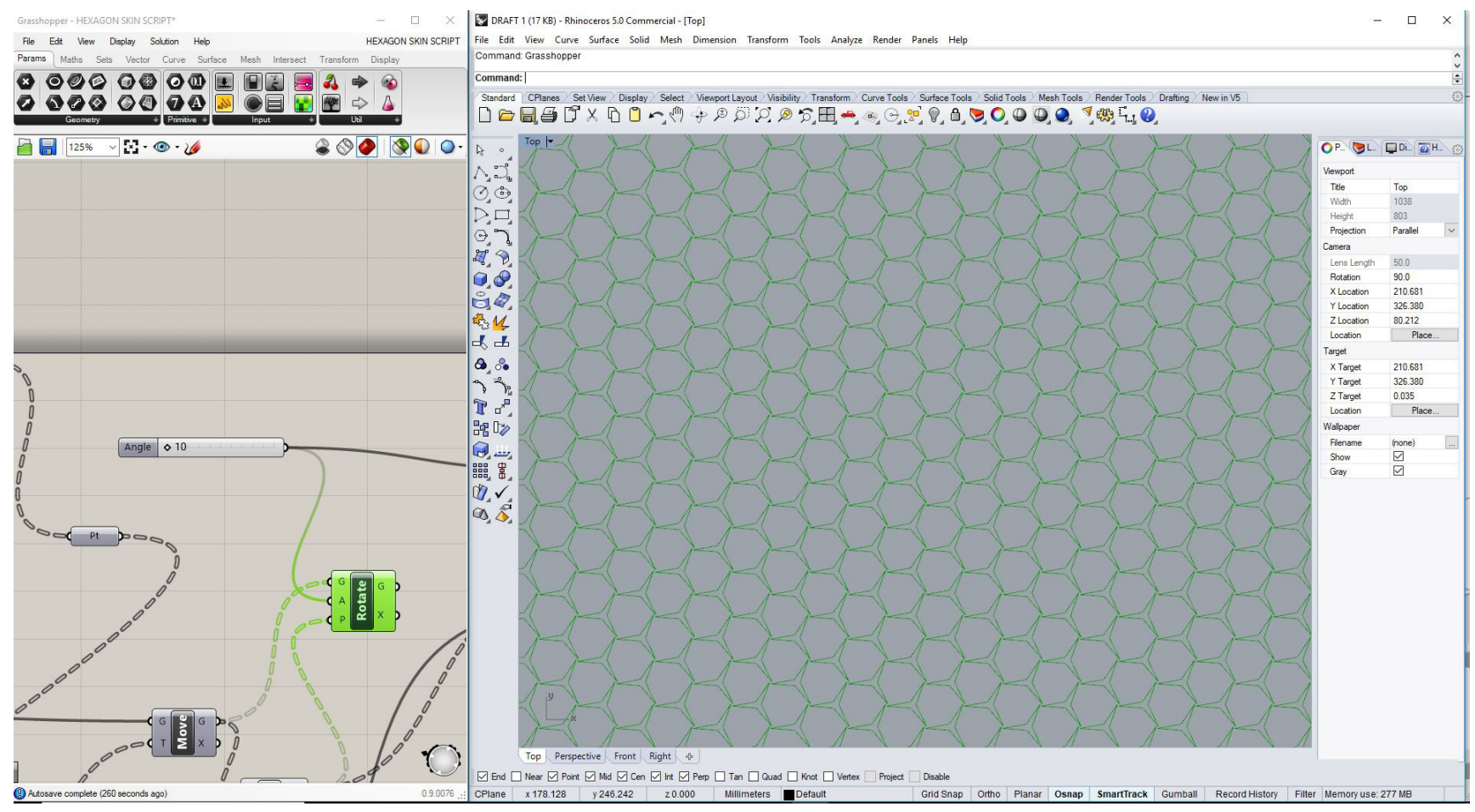

Fig. 18 The hexagonal grid. The pattern starts evolving as an attractor is introduced

sensors detect the user's presence/ movements, the units start rotating from its pivot point, creating a semi-permeable screen between the interior and the exterior, keeping the privacy of the user inside and at the same time not obstructing the view of the outdoors.
The third layer, which is also the outermost layer, is the opaque skin with the kinetic star modules that contract and expand, shown in Fig. 30(b). These are scripted to respond to heat and light from the sun; as a result, the units expand to minimise the light entering the interior 


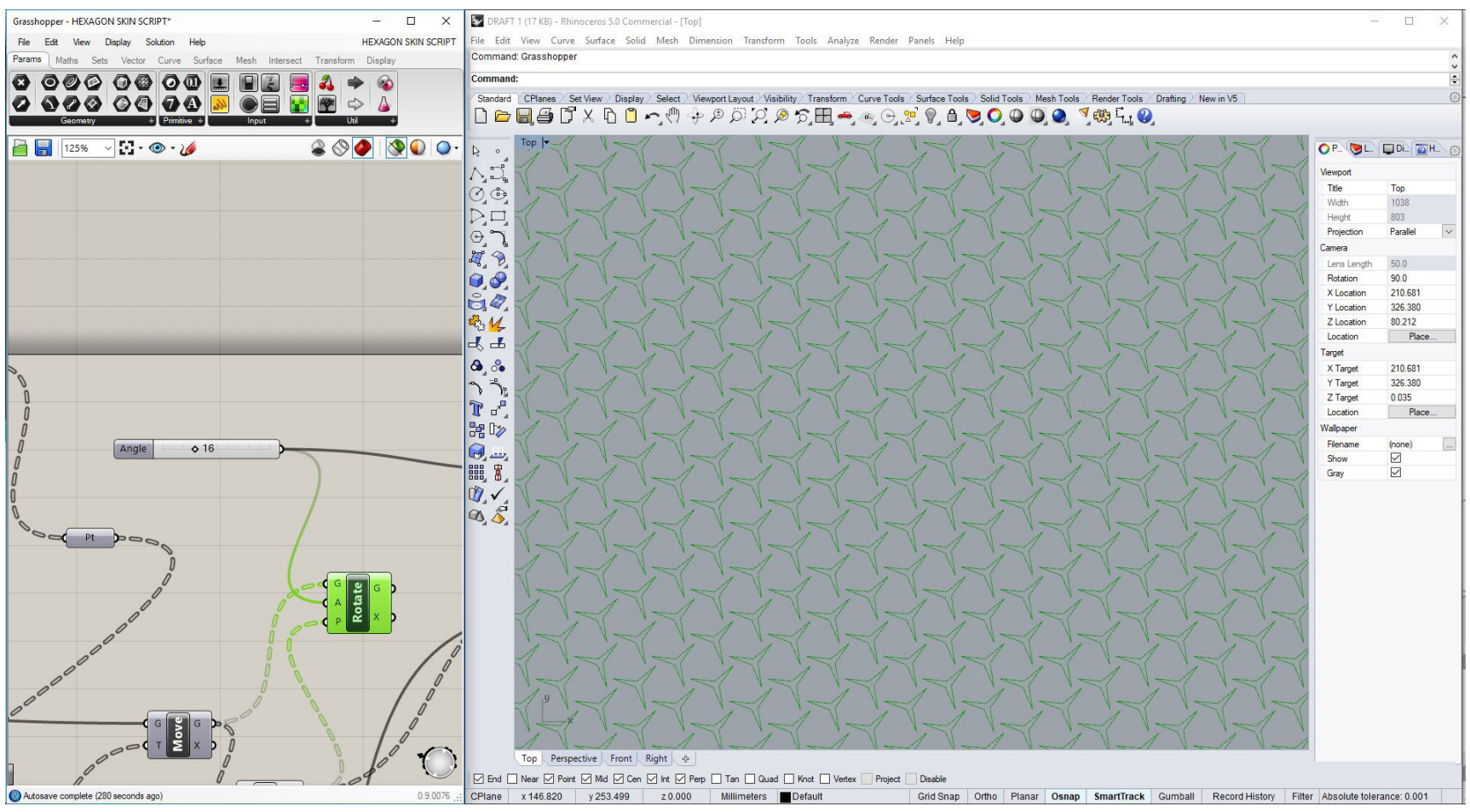

Fig. 19 The grid breaks as the module breaks and the components rotate

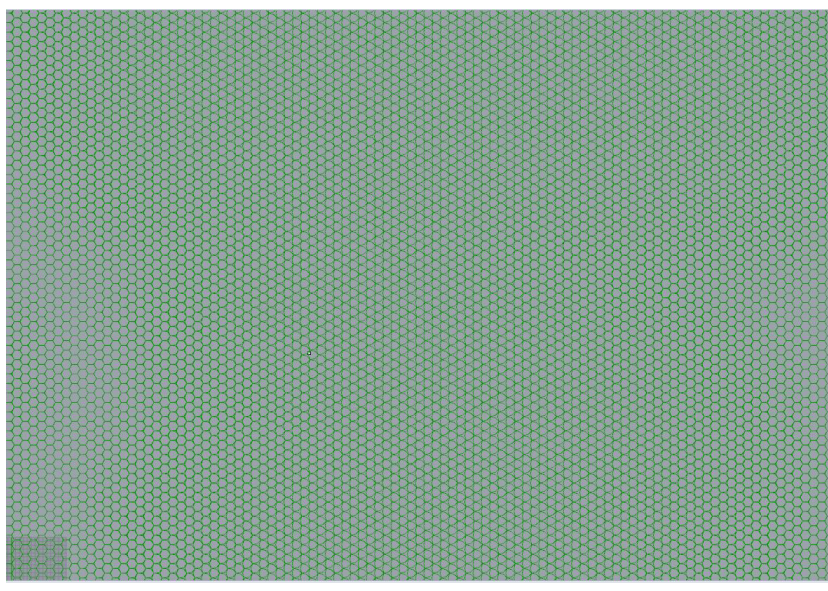

Fig. 20 All the edges are touching each other at the tangents, and the grid appears to be closed cells, almost like a hexagon grid

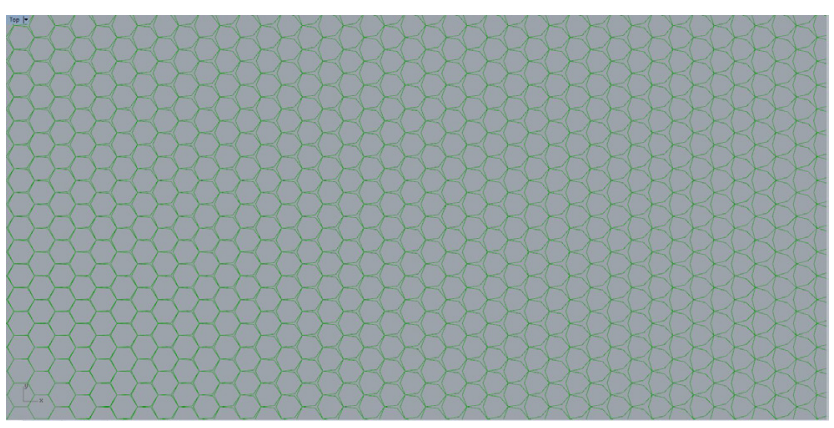

Fig. 21 The transformation starts appearing from left to right when an attractor or factor is introduced, changing the formation of the hexagonal grid and making triangular patterns

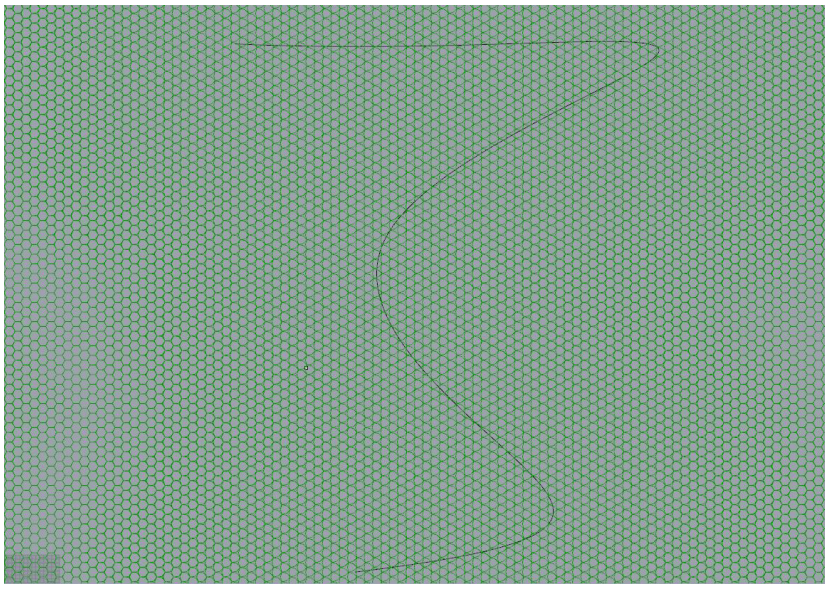

Fig. 22 As an interaction with the introduced parameter, the grid of modules reacts

spaces and also control heat. The shaded areas remain in their original state. These modules do not close completely; retaining a screen's unique character, they diffuse light and allow ventilation.

Mechanism: the screen is designed in three layers, first is the hexagonal grid that remains static. The second layer is the translucent skin, which is sensitive to motion and user interactive with sensors and the third is responsive to the sunlight. The two kinetic layers have a pivot point connected to the static grid, which acts as a base. The electric motor helps in the movement of the star-shaped triangular modules. 


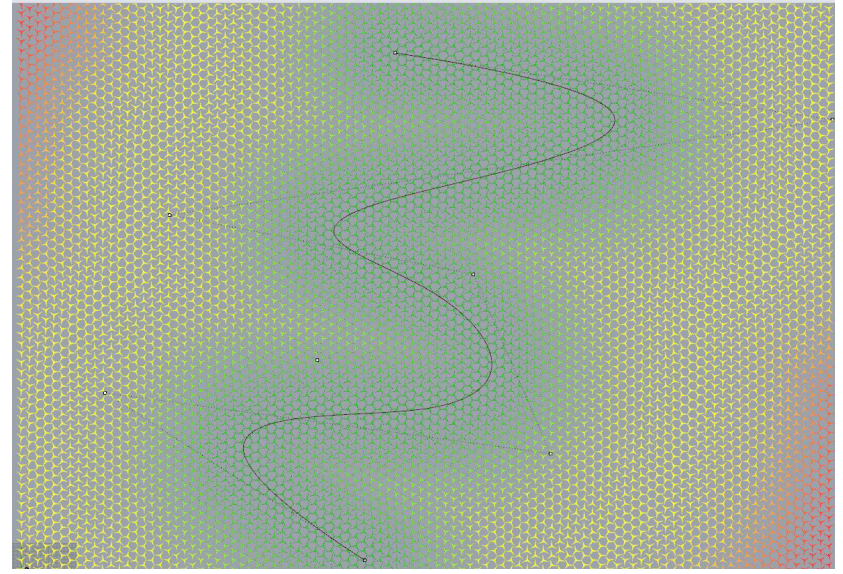

Fig. 23 A curve is then introduced as a field that will interact with this grid of modules and affect their state. This curve can be interpreted as any physical or social parameter as an input to disrupt the field.

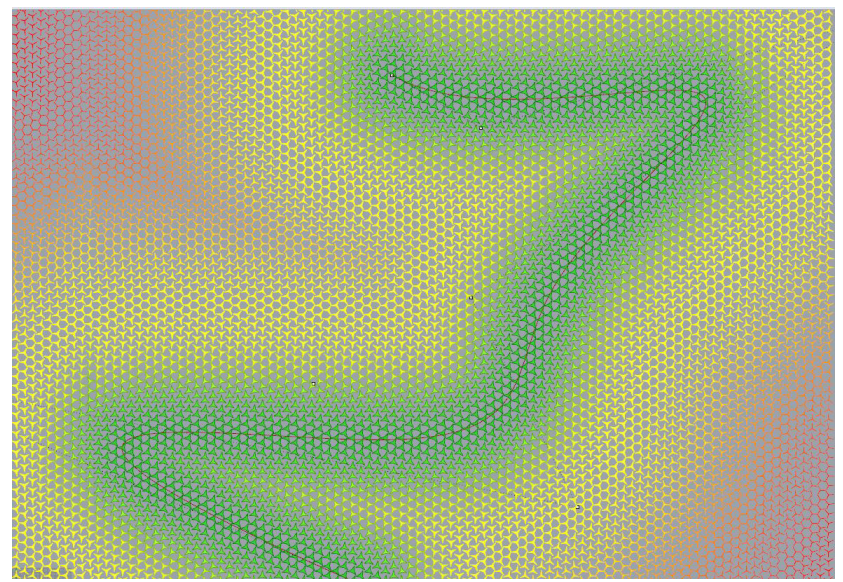

Fig. 24 Another layer is introduced to the modules as an interaction with the parameter curve

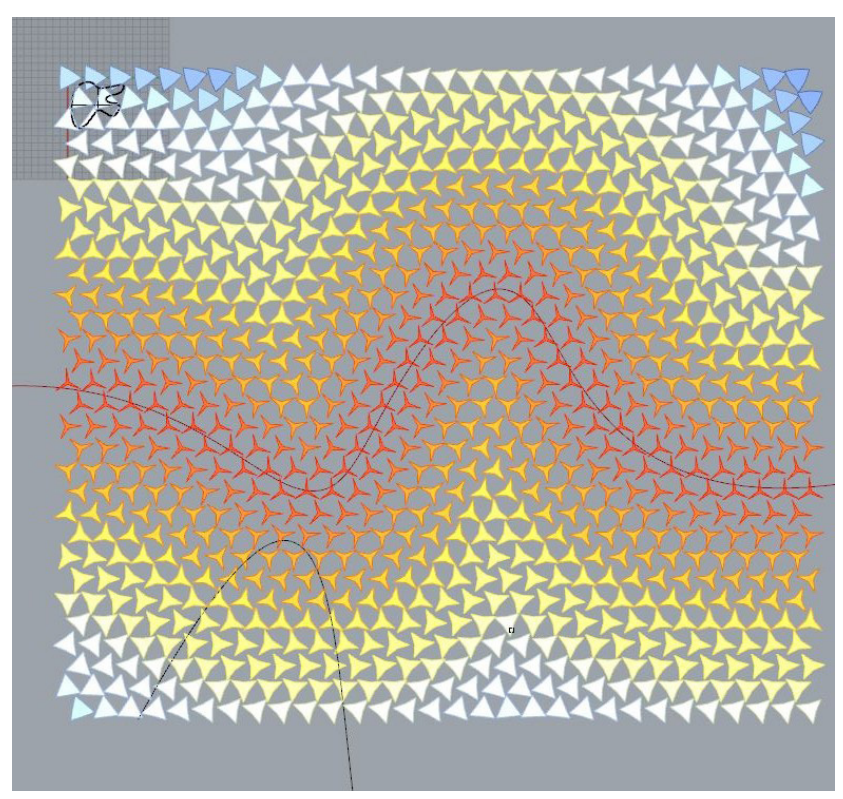

Fig. 25 The close-up shows the thickness gradually increasing as the modules get closer to the parameter curve

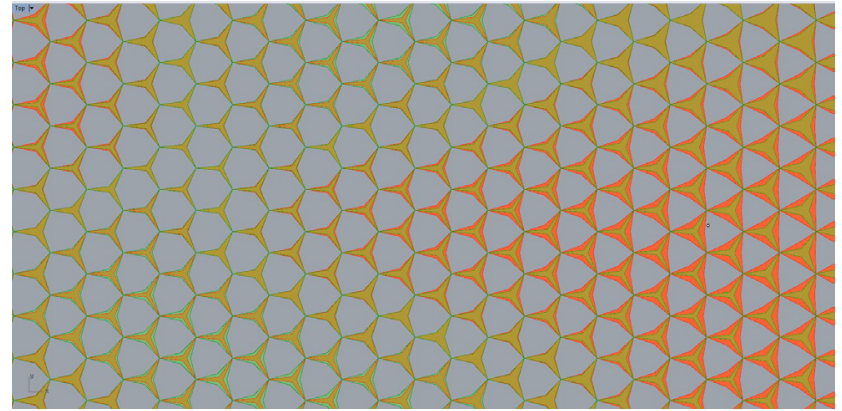

Fig. 26 The two overlapped grids

The second layer is the translucent layer that rotates on its pivot point and expands like the opaque third layer. The third layer of the screen remains static on its pivot point and expands and contracts depending on the sunlight. Figs. 31 and 32 shows the working of the screen's single module. Fig. 33 shows the three-dimensional drawing of the three layers of the screen and for further understanding a study model was developed as shown in Fig. 34.

\subsection{Application}

In conclusion, in this design, the module and its adaptation to the curve are easily achievable using motors as pivots for modules and a light sensor connected via a computer with the script. Even for the application in a live project, (Fig. 35), the technology required is currently available instead of some other adaptation techniques that require transformable materials. In terms of cost, this application is relatively cheap and easily applicable.

\section{Conclusion}

Façades or the building envelopes have always been the most significant feature of an architectural design, as it is not only the building's elevation, it is the interface between the building and the environment. With the changing time and evolution of technology, the focus remains on the façade design due to the numerous significant roles that a facade plays, as it is responsible for the thermal comfort, aesthetics, acoustics, and lighting of the building.

Energy conservation and optimisation have been an increasing concern over the last few decades. The ideas of sustainability and passive cooling techniques in design have once again gained popularity. Effective facades that are designed to adapt to environmental conditions are not a new phenomenon; they date back when windows and ventilators were designed carefully in response to the site conditions and environment. Architects and engineers aim to improve the interior spaces and thermal comfort, using 


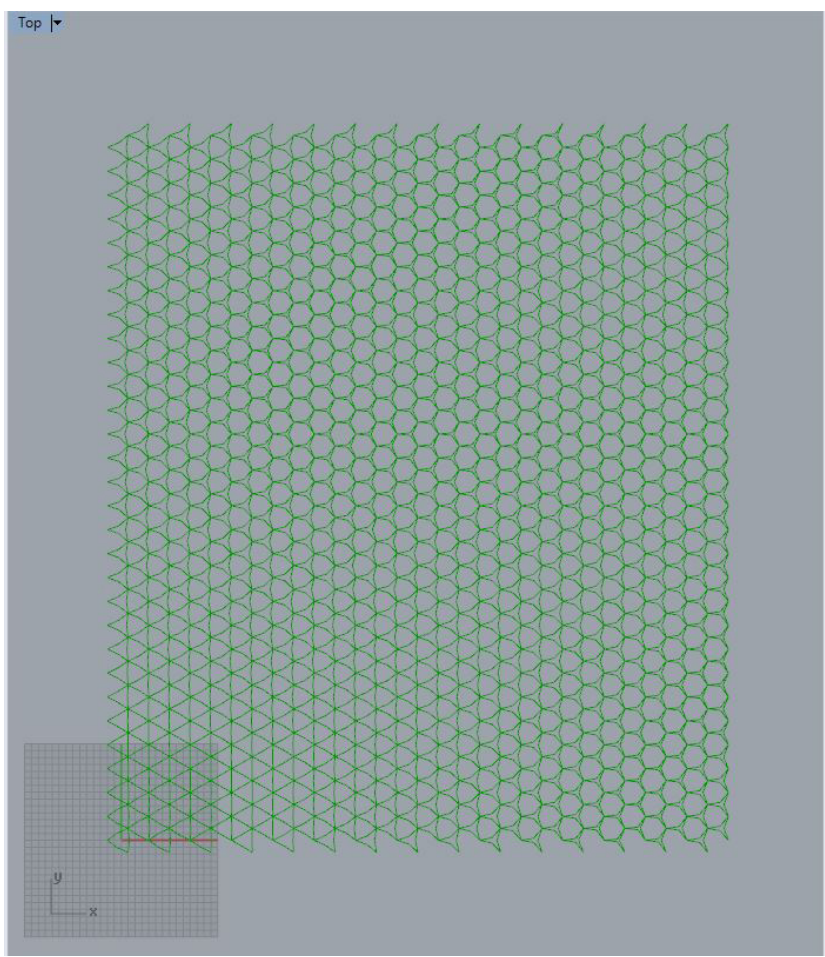

(a)

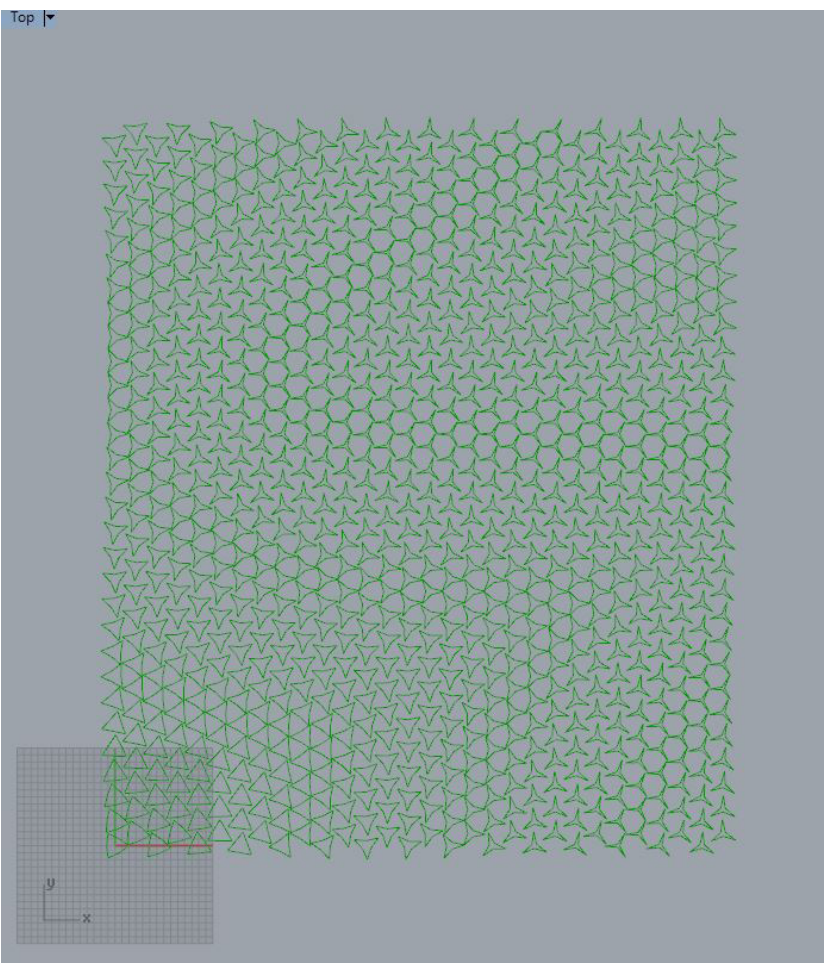

(b)

Fig. 27 These vertices are now joined (a) Using POLYLINE component to create the outline of the modules; (b) The rotation component is introduced to provide rotation to every module based on the amplitude calculated earlier

innovative, efficient systems or designs that eliminate or reduce the need to use mechanical heating or cooling.

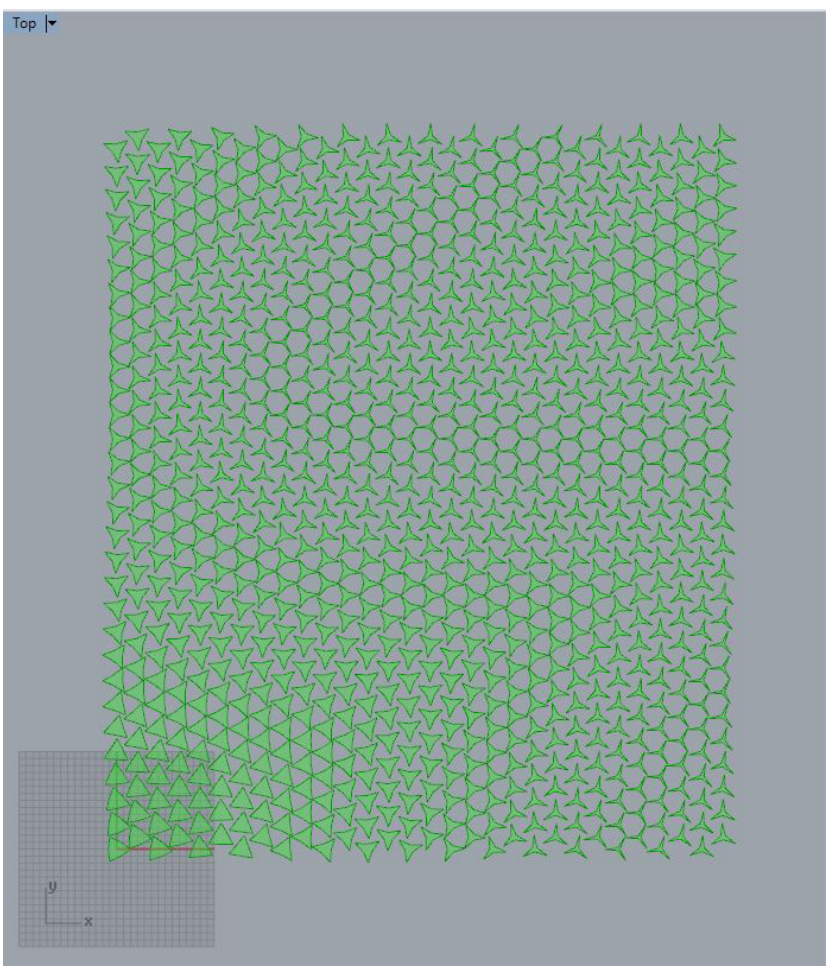

Fig. 28 Final outcome, a planar surface component is used to add the surface to the outlines

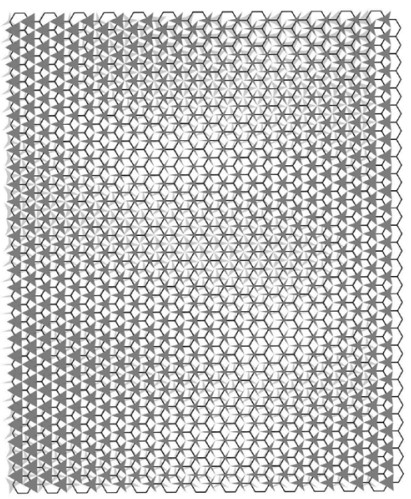

ELEVATION - OVERLAPPED

(a)

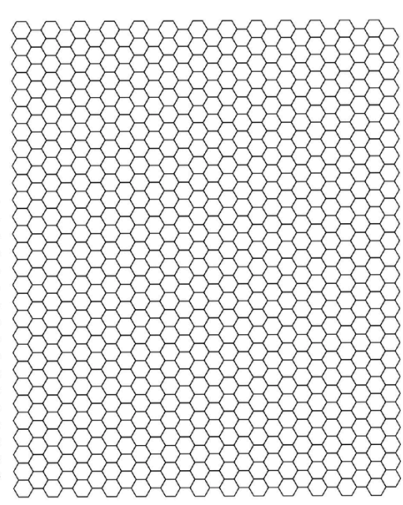

BACK GRID FOR SUPPORT
Fig. 29 The screen and its layers (a) The overlapped layered screen; (b) The hexagonal grid for the base. The static back grid for structural support.

As architects and engineers work more on the skin of the building, experimentation has resulted in high performance building facades, which have become one of the main focuses for researchers and designers. In high performance smart buildings, one of the main features are kinetic façades. Architects and engineers' fascination with the kinetic façade has existed for a long time, but now it has surpassed the aesthetic and is considered a vital element in design for environmental reasons. Kinetic façades are designed to be responsive to surroundings, having kinetic climate-adaptive elements including sensors and 


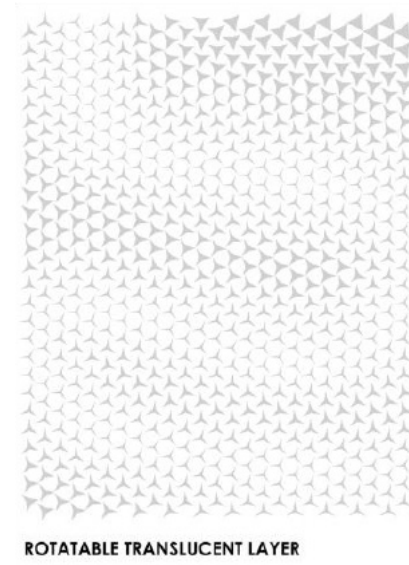

(a)

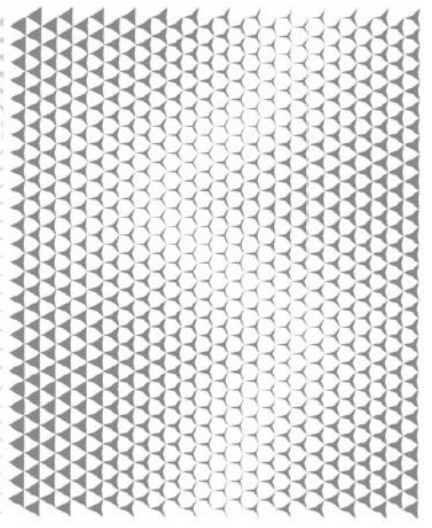

OPAQUE SHADOW CASTING LAYER

(b)
Fig. 30 The screen and its layers (a) the second skin, the rotatable translucent layer, is movement sensor-based and user interactive; (b) The opaque responsive layer of the screen.

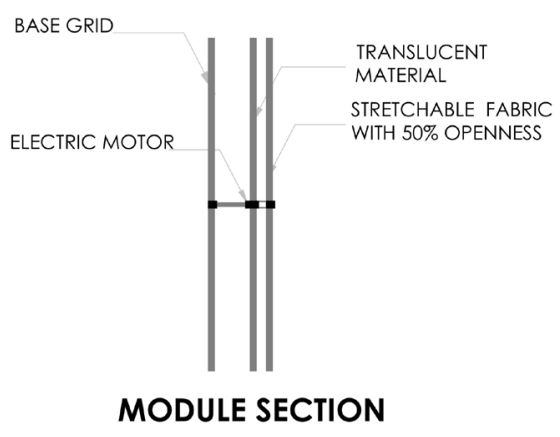

Fig. 31 The section of the module showing the base grid, the electric motor is the pivot point, the translucent screen and the final layer of the stretchable fabric

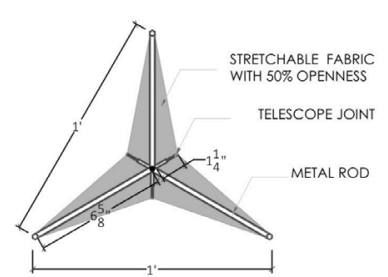

MODULE STRETCHED $10 \%$

(a)

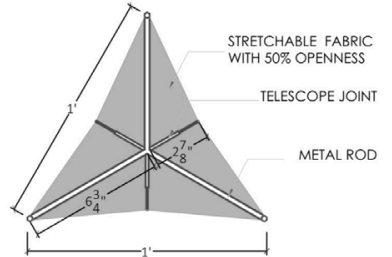

MODULE STRETCHED $80 \%$

(b)
Fig. 32 Single module details (a)The single module details when stretched $10 \%$; (b) The single module details when stretched $80 \%$. The metal rod creates the basic structure, along with the telescopic joints that help it to stretch and contract easily

automation, along with the user or designer's ability to dominate and control the settings.

The parametric designed kinetic façade has brought a dramatic change in the field of design and architecture. It has undoubtedly widened the design possibilities in the

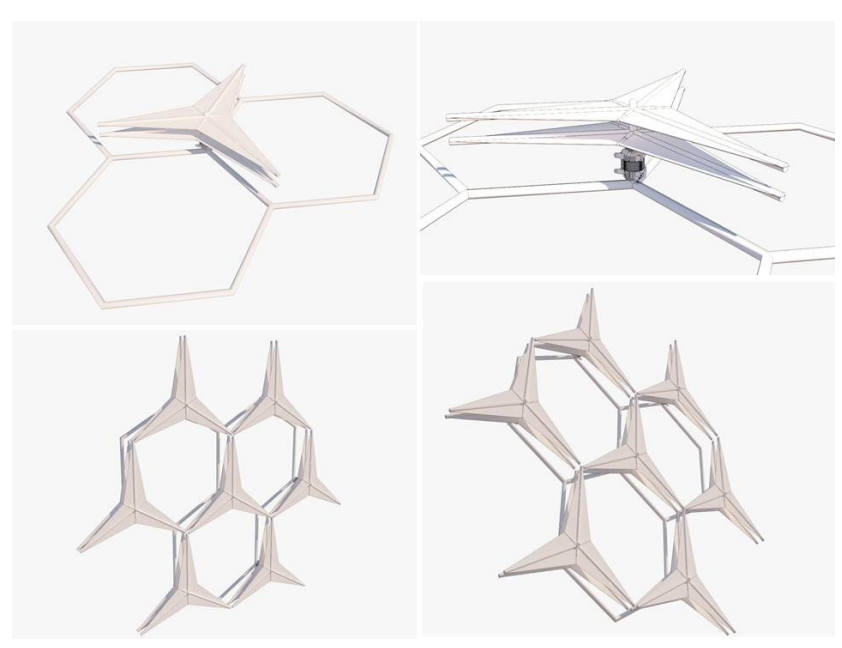

Fig. 33 The three-dimensional drawing of the three layers of the screen. The first, lower mesh is a hexagonal static grid that acts as a base for the two kinetic triangular modules that are attached to it.
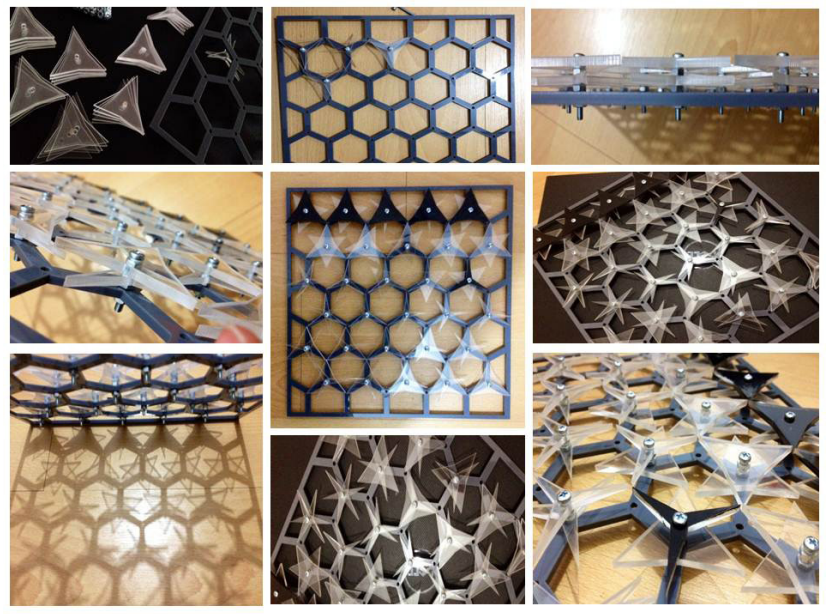

Fig. 34 Study model

mindset of architects and designers, as there is a shift from the conventional problem solving in a defined formal solution to an entirely new dimension where there are countless possible outcomes. Due to the advanced computational techniques, their role is confined to drawing shapes and has progressed to creating formal possibilities and more dynamic forms.

This exercise aims to revive the use of jali in the modern-day architectural design practice of façade design or a skin for a building. Jalis have been essential architectural elements of the Indian subcontinent due to their architectural significance of passive cooling properties and the cultural importance of privacy. In this study, the screens and the geometric patterns have been studied and analysed to understand its formation and tessellation, to proceed with the design case study to find possible new outcomes for façade design in the amalgamation of jali. 


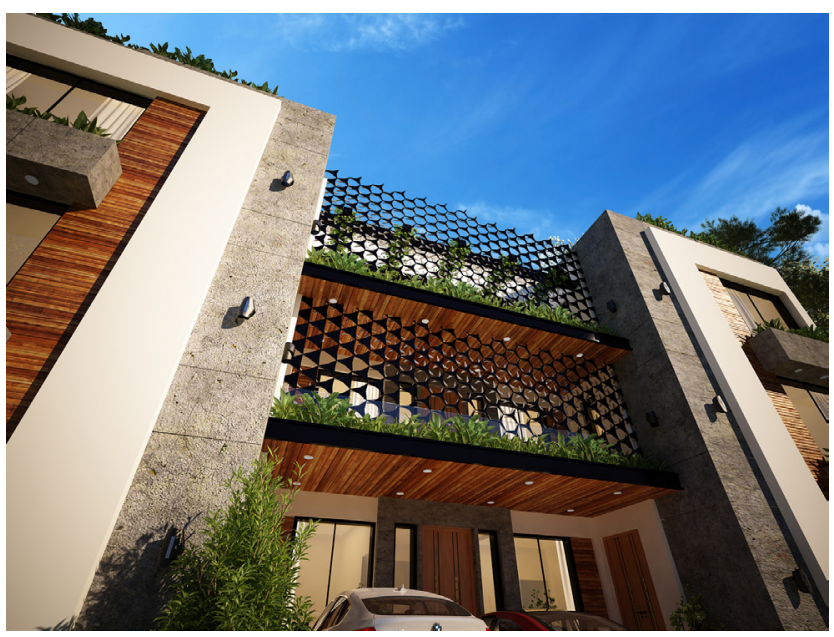

(a)

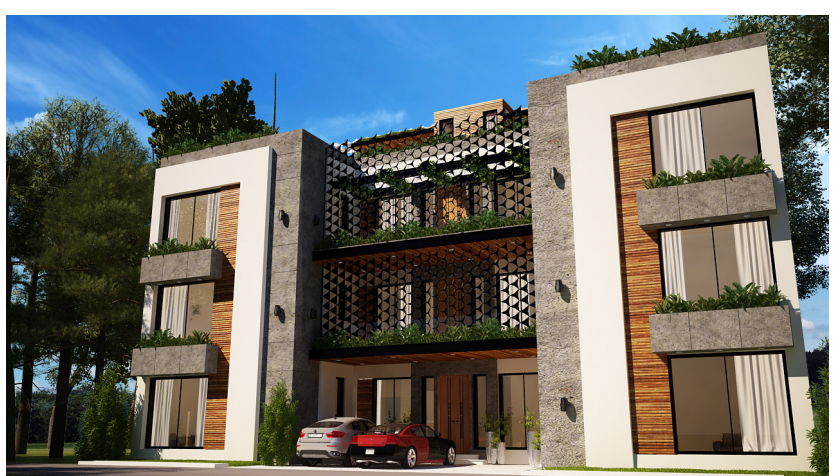

(b)

Fig. 35 The application of the designed three-layered screen on a conceptual building (screen designed by author on a building facade designed by Ishtiaq, 2017)

This research demonstrates the basic understanding of the parametric concept and the use of software in designing a kinetic facade. The two design exercises have been carried out to explore kinetic systems, with the potential of a simple geometric design used as a module to generate the skin and its kinetic response.

In both the design exercises, the hexagon grid is taken as a basic layout. The design focuses on the screen kinetics that are responsive to the light and privacy of the user. The screens are generated using Grasshopper, where they are introduced with an attractor curve, as an input, the responding factor. The interactions of these curves and the points of the vertices of the hexagonal grids' cells result in the kinetic movement of the screen, making it a living skin of the façade or an opening.

In Design 1, Fig. 16, the grid remains static, and the screens hexagonal cells respond like a camera's aperture, which expands and contracts in response to heat and light. It effectively controls the light entering the interior spaces, using materials with expanding and contracting properties, along with a hydraulic system to control the expansion and contraction of the opening. In this design, the screen becomes very opaque and obstructs the view; unlike a jali, the screen fulfills its purpose as a viewing curtain and a light diffuser.

In Design 2, Fig. 33, the base grid is static, and the other two layers are kinetic, one that rotates and expands without obstructing the view and one that only contracts/ expands to control the sunlight. This screen is also readily applicable as the technology required for this type of kinetic motion is currently available (as opposed to some other adaptation techniques with required transformable materials); it is achievable by using motors as pivots for modules and a light sensor connected via a computer with the script. With the present examples of kinetics in architectural design, the kinetic façade is the new present and the coming future of façades. It is constantly progressing and putting forward new challenges, addressing new problems and finding new solutions, making the best use of resources to achieve harmony with the environment where the building is placed. So far, in this era of kinetic façade design and fascination, it cannot be concluded that a perfect solution or formula has been achieved. One cannot simply say which is the best model to use or which design has the best environmentally responsive approach, as all these designs are different in nature and differ in the context in which they are placed. As a result, we can look at all these existing designs in order to study them, and as models to analyse, to find out which approach best works for user comfort along with the environmental context it was placed in, and the results that these projects have in terms of optimising energy efficiency.

It can be concluded from these investigations that if further research and design exercises are performed using various geometrical patterns, unlimited solutions and screen forms can be achieved. The single module taken from a conventional screen can be the basic pattern generator and transformation in a parametric design for a screen or skin of facade or the facade itself. The numerous computer-generated solutions and options have opened a gateway for further explorations in the field of design, which undoubtedly leaves us more inquisitive. The investigations carried out in this research are significant in terms of the potential use of screens in modern architectural practices in responsive facades, using parametric patterns. 


\section{References}

Alhadi, R. (2011) "The Living Skyscraper; Mashrabbia; A Kinetic Envelope Represents Islamic Culture and Improves Building Energy Performance", MArch, The Savannah College of Art and Design. [online] Available at: http://ecollections.scad.edu/iii/cpro/ app\%3Fid\%3D9304975483529753\%26itemId\%3D1000574\%261a ng\%3Deng\%26service\%3Dblob\%26suite\%3Ddef [Accessed: 24 October 2021]

Alkhayyat, J. M. J. (2013) "Design strategy for adaptive kinetic patterns: creating a generative design for dynamic solar shading systems", MSc Digital Architecture, University of Salford. [online] Available at: https://www.academia.edu/6978438/Design_strategy_for_ adaptive_kinetic_patterns_creating_a_generative_design_for_ dynamic_solar_shading_system [Accessed: 24 October 2021]

Avermaete, T. (2018) "The socius of architecture: spatialising the social and socialising the spatial", The Journal of Architecture, 23(4), pp. $537-542$.

https://doi.org/10.1080/13602365.2018.1479353

Böke, J., Knaack, U., Hemmerling, M. (2019) "State-of-the-art of intelligent building envelopes in the context of intelligent technical systems", Intelligent Buildings International, 11(1), pp. 27-45. https://doi.org/10.1080/17508975.2018.1447437

Ekhtiar, M. D., Moore, C. (2012) "Art of the Islamic World: A Resource for Educators", The Metropolitan Museum of Art, New York, NY, USA. [online] Available at: https://www.metmuseum.org/art/ metpublications/Art_of_the_Islamic_World_A_Resource_for_ Educators [Accessed: 24 October 2021]

Gallas, M. A., Jacquot, K., Jancart, S., Delvaux, F. (2015) "Parametric Modeling: An Advanced Design Process for Architectural Education", In: 33rd eCAADe Conference, Vienna, Austria, pp. 149-157. [online] Available at: http://papers.cumincad.org/cgibin/works/paper/ecaade2015_248 [Accessed: 24 October 2021]

Hassan, J. (2014) "File: Naulakha Pavilion in Lahore Fort (cropped). jpg", [digital photograph], Wikipedia. [online] Available at: https:// en.wikipedia.org/wiki/File:Naulakha_Pavilion_in_Lahore_Fort_ (cropped).jpg [Accessed: 24 October 2021]

Hoberman, C., Schwitter, C. (2008) "Adaptive Building Initiative", [online] Available at: https://dezignark.com/blog/current-workchuck-hoberman-and-craig-schwitter-adaptive-building-initiative/ [Accessed: 24 October 2021]

Hoberman, C. (2010) "Dynamic windows", [digital image], [online] Available at: https://www.hoberman.com/portfolio/dynamic-windows/ [Accessed: 24 October 2021]

Kelly, T. (2013) "Unwritten Procedural Modeling with the Straight Skeletons", PhD Thesis, School of Computing Science, College of Science and Engineering, University of Glasgow. [online] Available at: https://vcg.leeds.ac.uk/projects/unwritten-procedural-modeling-with-the-straight-skeleton/ [Accessed: 24 October 2021]

Lang, W. (2017) 'Is it all 'just' a façade? The functional, energetic and structural aspects of the building skin", In: Schittich, C. (ed.) in DETAIL: Building Skins, Birkauser, Basel, Switzerland, pp. 28-45. [online] Available at: https://issuu.com/detail-magazine/docs/978-37643-7640-6-bk-en-building_sk [Accessed: 24 October 2021]

Leatherbarrow, D., Mostafavi, M. (2005) "Surface Architecture", MIT Press, Cambridge, MA, US.
Loonen, R. C. G. M. (2010) "Climate adaptive building shells: what can we simulate?", MSc Thesis, Eindhoven University of Technology. [online] Available at: https://research.tue.nl/en/studentTheses/climate-adaptive-building-shells [Accessed: 24 October 2021]

Lupton, E., Tobias, J., Imperiale, A., Jeffers, G., Mates, R. (2002) "Skin: Surface, Substance, and Design", Princeton Architectural Press, New York, NY, USA.

Makert, R., Alves, G. (2016) "Between Designer and Design: Parametric Design and Prototyping Considerations on Gaudís Sagrada Familia", Periodica Polytechnica Architecture, 47(2), pp. 89-93. https://doi.org/10.3311/PPar.10335

Michler, A. (2010) "Jean Nouvel's stunning museum facade dilates to let in daylight", [digital image]. Inhabit, [online] Available at: https:// inhabitat.com/?attachment_id=162025 [Accessed: 24 October 2021]

Moloney, J. (2009) "A Morphology of Pattern for Kinetic Facades", In: Tidafi, T., Dorta, T. (eds.) Joining Languages, Cultures and Visions: CAADFutures 2009, Presses Universitaires du Mirail Toulouse (PUM), Toulouse, France, pp. 200-213. [online] Available at: http://cumincad.scix.net/data/works/att/cf2009_200.content. pdf [Accessed: 24 October 2021]

Moloney, J. (2011) "Designing Kinetics for Architectural Facades: State Change", Routledge, London, UK. https://doi.org/10.4324/9780203814703

Nady, R. (2017) "Dynamic Facades: Environmental Control Systems for Sustainable Design, Renewable Energy and Sustainable Development, 3(1), pp. 118-127. https://doi.org/10.21622/resd.2017.03.1.118

Okba, E. M. (2005) "Building envelope design as a passive cooling technique", In: International Conference "Passive and Low Energy Cooling for the Built Environment", Santorini, Greece, pp. 467-473. [online] Available at: https://www.aivc.org/resource/building-envelope-design-passive-cooling-technique [Accessed: 24 October 2021]

Park, J. W, Huang, J., Terzidis, K. (2011) "A Tectonic Approach for Intehrating Kinesis with a Building in the Design Process of Interactive Skins", Journal of Asian Architecture and Building Engineering, 10(2), pp. 305-312.

https://doi.org/10.3130/jaabe.10.305

Reki, M., Selçuk, A. S. (2018) "Evolution of Geometric Patterns in the Islamic World and a Case Study on the Jalis of the Naulakha Pavilion in the Lahore Fort", Gazi University Journal of Science Part B: Art Humanities Design and Planning, 6(2), pp. 83-97. Available at: http://dergipark.org.tr/en/pub/gujsb/ issue/38005/414643 [Accessed: 24 October 2021]

Schittich, C. (2017) "Shell, Skin, Materials", In: Schittich, C. (ed.) in DETAIL: Building Skins, Birkauser, Basel, Switzerland, pp. 8-27. [online] Available at: https://issuu.com/detail-magazine/docs/9783-7643-7640-6-bk-en-building_sk [Accessed: 24 October 2021]

Sharaidin, K. (2014) "Kinetic façades: Towards design for environmental performance", $\mathrm{PhD}$ Thesis, School of Architecture and Design, RMIT University. Available at: https://practice-research.com/ portfolio-item/kinetic-facades-towards-design-for-environmental-performance-by-kamil-sharaidin/ [Accessed: 24 October 2021] 
Stolarewicz, M. (2012) "Time as a Designing Factor in Architecture Creation: Application of parametric design in dynamic facades", New Design Concepts and Strategies, eCAADe 30(2), pp. 551-556. [online] Available at: http://papers.cumincad.org/data/works/att/ ecaade2012_54.content.pdf [Accessed: 24 October 2021]

Sullivan, C. C. (2006) "Robo Buildings. Pursuing the Interactive Envelope", Architectural Record, 19, pp. 149-156. [online] Available at: https://facades.lbl.gov/cec-electrochromics/refs/ attachmt17.10_archrec.pdf [Accessed: 24 October 2021]

Taleb, H. M., (2014) "Using passive cooling strategies to improve thermal performance and reduce energy consumption of residential buildings in U.A.E. buildings", Frontiers of Architectural Research, 3(2), pp. 154-165.

https://doi.org/10.1016/j.foar.2014.01.002
Wagner, O. (1988) "Modern architecture: A guidebook for his students to this field of art", The Getty Center for the History of Art and the Humanities, Santa Monica, CA, USA.

Wigginton, M., Harris, J., (2002) "Intelligent Skins", Architectural Press, Amsterdam, Netherlands.

Yi, H., Kim, M. J., Kim, Y., Kim, S. S., Lee, K. I. (2019) "Rapid Simulation of Optimally Responsive Façade during Schematic Design Phases: Use of a New Hybrid Metaheuristic Algorithm", Sustainability, 11(9), Article number: 2681. https://doi.org/10.3390/su11092681

Zuk, W., Clark, R. H., (1970) "Kinetic Architecture", Van Nostrand Reinhold, New York, NY, USA. 